Review

\title{
Sensors for product characterization and quality of specialty crops-A review
}

\author{
M. Ruiz-Altisent ${ }^{\mathrm{a}, *}$, L. Ruiz-Garcia ${ }^{\mathrm{a}}$, G.P. Moreda ${ }^{\mathrm{a}}$, Renfu Lu $^{\mathrm{b}}$, N. Hernandez-Sanchez ${ }^{\mathrm{a}}$, \\ E.C. Correa ${ }^{a}$, B. Diezma ${ }^{\mathrm{a}}$, B. Nicolaï ${ }^{\mathrm{c}}$, J. García-Ramos ${ }^{\mathrm{d}}$ \\ a Laboratorio de Propiedades Físicas y Tecnologías Avanzadas en Agroalimentación, Universidad Politécnica de Madrid, ETSI Agrónomos, Edificio Motores, \\ Avda. Complutense s/n, 28040 Madrid, Spain \\ b USDA/ARS Sugarbeet \& Bean Research Unit, 224 Farrall Hall, Michigan State University, East Lansing, MI 48824, USA \\ ${ }^{c}$ Flanders Centre of Postharvest Technology/BIOSYST-MeBioS, Catholic University of Leuven, Willem de Croylaan 42, 3001 Leuven, Belgium \\ ${ }^{\mathrm{d}}$ Agriculture and Agricultural Economy Department, University of Zaragoza, 22071 Huesca, Spain
}

\section{A R T I C L E I N F O}

\section{Article history:}

Received 5 February 2009

Received in revised form 15 July 2010

Accepted 17 July 2010

\section{Keywords:}

Non-invasive

Vision

Spectroscopy

Near-infrared

Optical

Magnetic resonance

\begin{abstract}
A B S T R A C T
This review covers developments in non-invasive techniques for quality analysis and inspection of specialty crops, mainly fresh fruits and vegetables, over the past decade up to the year 2010. Presented and discussed in this review are advanced sensing technologies including computer vision, spectroscopy, $\mathrm{X}$-rays, magnetic resonance, mechanical contact, chemical sensing, wireless sensor networks and radiofrequency identification sensors. The current status of different sensing systems is described in the context of commercial application. The review also discusses future research needs and potentials of these sensing technologies. Emphases are placed on those technologies that have been proven effective or have shown great potential for agro-food applications. Despite significant progress in the development of non-invasive techniques for quality assessment of fruits and vegetables, the pace for adoption of these technologies by the specialty crop industry has been slow.
\end{abstract}

(C) 2010 Elsevier B.V. All rights reserved.

\section{Contents}

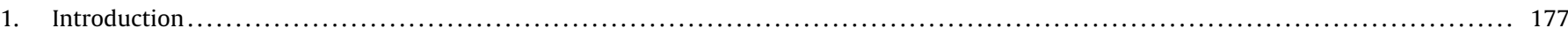

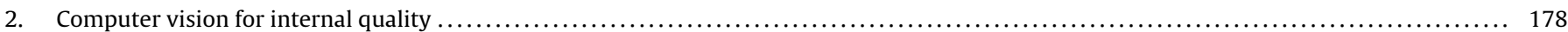

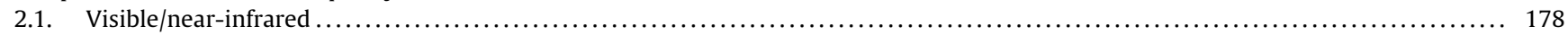

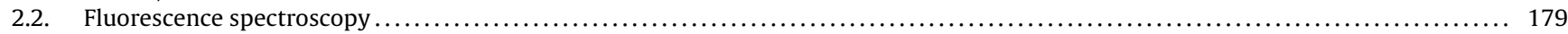

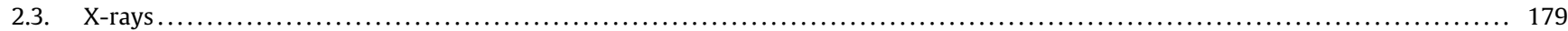

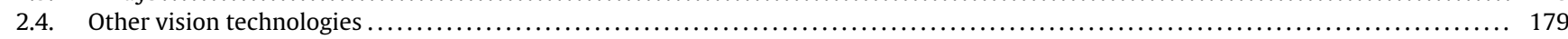

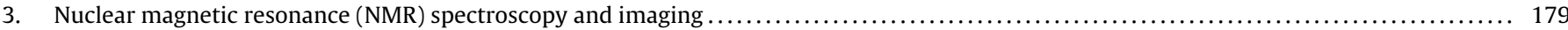

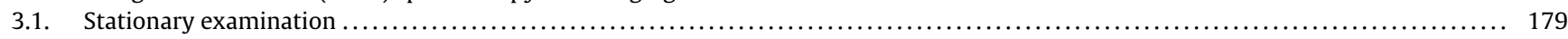

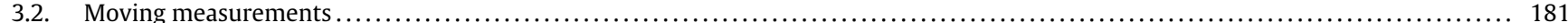

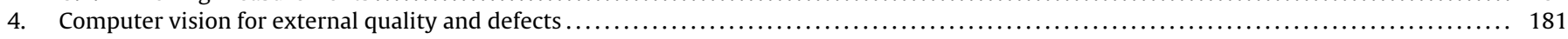

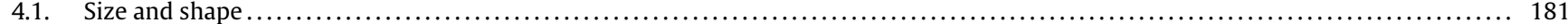

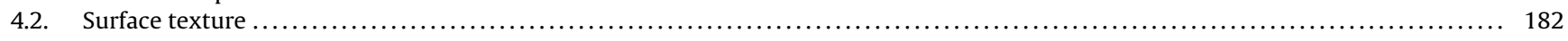

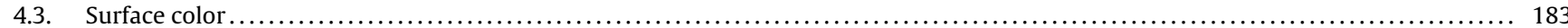

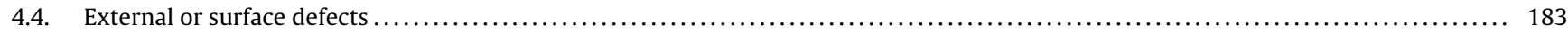

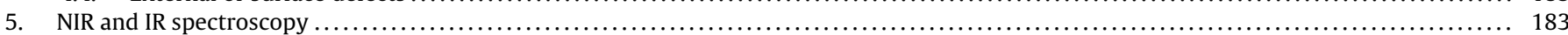

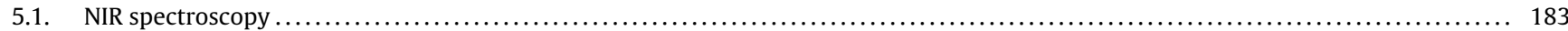

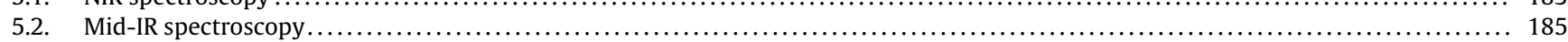

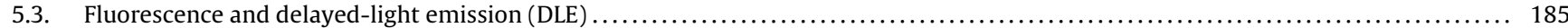

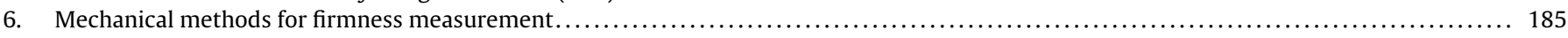

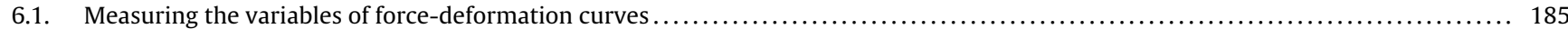

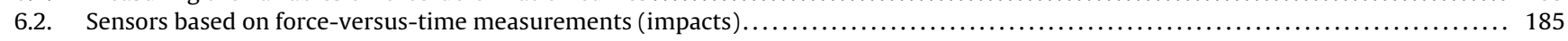

\footnotetext{
* Corresponding author. Tel.: +34 913365855; fax: +34 913365845

E-mail address: margarita.ruiz.altisent@upm.es (M. Ruiz-Altisent).
} 


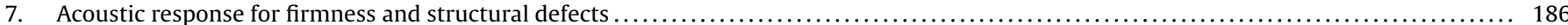

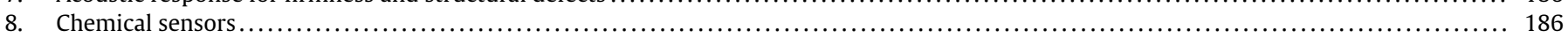

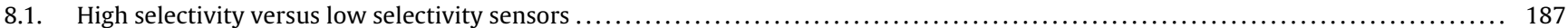

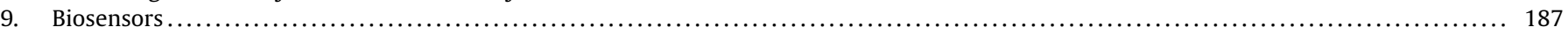

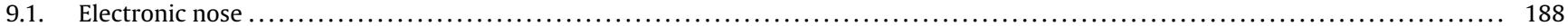

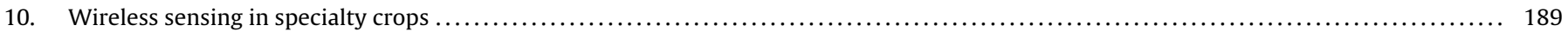

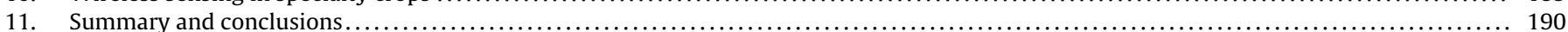

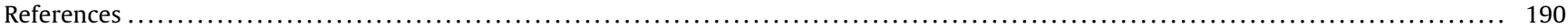

\section{Introduction}

Fifty years ago, a new approach to characterizing fresh food materials was created, which treated food items as physical bodies to which conventional engineering concepts and methods could be applied. The aim was to maintain and enhance the quality of food products as they go through different stages of operation from harvest to postharvest handling to retailing.

Specialty crops are defined as "fruits and vegetables, tree nuts, dried fruits and horticulture and nursery crops, including floriculture" (USDA, 2004). Non-destructive (ND) testing for properties and characteristics of specialty crops is critical for monitoring and controlling product quality and safety. Sensors play the key role in identification of product properties, and thus they have been an active research area, as evidenced by thousands of engineering research publications during the past 50 years.

Quality sensing is needed or desired for most or all agricultural commodities or foods at different stages of the production/marketing chain. Specialty crops cover a wide, diverse variety of commodities, which differ greatly in morphology, composition, and physiology. Hence it is customary to classify them into different groups according to a specific criterion. Temperate fruits, including apple, peach, pear, citrus, and table grape, are harvested manually for fresh consumption, or mechanically for processing. Tropical fruits including avocado, banana, mango, and papaya are also hand harvested, while dry (shell) fruits or nuts are often machine harvested. We should also mention that olive and grape are two fruit crops of world significance; they are mainly machine harvested, where sensors are being introduced for quality monitoring. Vegetables contain even a much greater number of commodities; they are cultivated in different types of environments, including greenhouse. For example, there are fruit vegetables (e.g., tomato, bell pepper, zucchini) and green leafy vegetables (e.g., lettuce, spinach, cabbage, small greens). Finally, ornamentals refer to potted flowers, potted green plants and cut flowers.

After harvest, specialty crops may undergo all or part of these postharvest operations before being delivered to the consumer: pre-sorting, sorting, washing, refrigeration, grading (for quality classes), wrapping, and packaging (placing into cartons, small boxes, baskets, bags, nets, etc.), cold-storage (for short term, i.e., days) or controlled or modified-atmosphere storage (for long term, i.e., months). In addition, some commodities need such special treatments as ripening using gases and temperature (peaches, citrus, bananas), individual wrapping (lettuce, broccoli, cauliflower, bell peppers), cutting and small-bag wrapping (lettuce, mixed salads, fruits), or destruction (e.g., for olive oil and wine grape). Ornamental crops represent a large share of the total production for the specialty crop industry. But there is still a lack of research and progress on development of sensors for ornamental crops, except for automatic production and handling systems which have been widely adopted by the industry.

Specialty crops are living biological products that the consumer expects them to be in the best quality and safety condition. Freshness and quality, which are important to the consumer, are affected by time, handling procedure, environmental conditions, and the processes to which they undergo. At each of these steps, the freshness and quality of specialty crop products need to be monitored and controlled. Traditional manual expertise for quality inspection is no longer adequate nowadays, and only sensors can provide solutions for monitoring and controlling the quality of specialty crops.

A number of reviews on non-invasive, fast technologies for fruit and vegetables quality sensing have been published (Chen and Sun, 1991; Abbott et al., 1997; Studman, 2001; Butz et al., 2005). Many of these review papers covered a broad range of sensing techniques, with a selected few that also discussed the feasibility of these techniques for industrial applications (Abbott, 2004; Walsh, 2005). Moreover, several recent reviews are focused on selected techniques, such as mechanical methods for firmness measurement (García-Ramos et al., 2005), size characterization techniques (Moreda et al., 2009), computer vision (Brosnan and Sun, 2002; Du and Sun, 2006), near-infrared (NIR) spectroscopy (Nicolai et al., 2007), nuclear magnetic resonance (NMR) (Aristizábal, 2007), biosensing (Mello and Kubota, 2002; Patel, 2002), wireless sensing (Ruiz-Garcia et al., 2009), and plant diseases detection (Sankaran et al., 2010). The needs for this area of research are mainly driven by the specialty crop industries to meet increasing consumer demand for better quality and safer fresh products.

A large number of recent publications on non-destructive detection of food quality are related to the utilization of electromagnetic radiation in a wide range of frequencies. Electromagnetic radiationbased technologies have shown great potential; some of them have been successfully used for monitoring the quality of specialty crops. Successful application of these technologies requires the combination of effective sensors with sophisticated mathematical models and computer algorithms to establish relationships between selected physical/chemical properties and quality attributes of the product. As a result, a large number of papers published recently are focused on utilizing different non-destructive (ND) optical techniques for quality detection of agro-food products. Great advances have been made in spectroscopy and computer vision, and these techniques are being widely used for quality inspection and control of products in many industries including food. As technologies based on VIS, NIR, mid-infrared (MIR), and ultra-violet (UV) are becoming more affordable and equipped with more user-friendly data treatment and calibration capabilities, they have fostered further development of detection procedures for different quality- and composition-related properties of fruits and vegetables.

Over the past 10 years, a number of new technologies based on electromagnetic properties have emerged, whereas great progress has also been made on other existing technologies. They include $\mathrm{X}$-ray, nuclear magnetic resonance (NMR) or magnetic resonant imaging (MRI), fluorescence, and with less success until now, electrical impedance and permittivity (mainly microwave), thermal sensing and selective gas/volatile sensing. These developments have opened new areas of research as well as new applications for sensing quality of specialty crops.

This review covers different sensing techniques, with emphasis on those emerging technologies like NMR, MRI, wireless sensor networks (WSN) and radio-frequency identification (RFID), for fruits and vegetables and their potential for industrial applications. 


\section{Computer vision for internal quality}

Numerous review articles have been published on computer vision technology for quality inspection of food and agricultural products (Chen et al., 2002; Brosnan and Sun, 2004; Aguilera and Briones, 2005) and horticultural products in particular (Abbott, 2004; Butz et al., 2005; Nicolai et al., 2007). This section provides a brief review of selected vision technologies, especially those emerging technologies that are showing great promise for assessing internal quality of horticultural products, i.e., sensory attributes (texture and flavor), nutritive values, chemical constituents, functional properties and internal defects or physiological disorders.

\subsection{Visible/near-infrared}

The reflectance properties of a product in the visible region (approximately $400-780 \mathrm{~nm}$ ) are perceived by humans as color, which provide pigment information about commodities. Skin color has been considered indicative of maturity for some horticultural products such as banana, mango, and tomato (Edan et al., 1997). Color, in the human perception directly relates to product appearance (Abbott, 1999), and the relationship of pigments, and therefore the VIS reflectance fingerprint, with deterioration and evolution of fruits during ripening has been established. Many constituents of fruit quality, including those that contribute to taste and aroma as well as antioxidant potential are synthesized in chloroplasts or chromoplasts, and in the genes (Barry, 2009). In the food industry, quality factors are often linked to product pigments or color features. VIS imaging sensors are thus effective techniques for quality detection of fruits, especially for maturity and ripeness. Similar results have been established in green plants.

Broadband images (i.e., gray-scale and color images) are inappropriate for detecting specific quality attributes (other than color attributes or certain surface blemishes that are visible) because many chemical components (pigments, sugar, starch, water, protein, etc.) are sensitive to specific narrow wavebands in or beyond the visible region. Hence spectral imaging technology, which acquires single or multiple images at selected wavelengths, is used for detection of specific quality attributes of horticultural products. Spectral imaging may be categorized into multispectral and hyperspectral. Multispectral imaging acquires spectral images at a few discrete narrow wavebands (the bandwidth may range between 5 and $50 \mathrm{~nm}$ ). Hyperspectral imaging, on the other hand, acquires tens or hundreds of spectral images at congruous wavelengths or wavebands over a specific spectral region.

Multispectral imaging has been used to detect quality-related chemical components, such as fruit pigment concentration, and distribution of sugar (or soluble solids) in fruits (Peng and Lu, 2007). Since color measurements usually give poor results for ripeness assessment and defect detection, NIR multispectral imaging technology has been developed and is now commercially available for fruit blemish detection. The technology can achieve up to $90 \%$ accuracy in detecting damaged fruits with visible blemishes of greater than $5 \mathrm{~mm}$ in diameter. Research also showed that multispectral scattering images can be used to evaluate the firmness of fruits (Peng and Lu, 2007; Qing et al., 2007). The technique uses either a regular digital camera or a multispectral imaging device to capture spectral scattering images from the surface of a fruit generated by a focused light beam (either monochromatic such as laser or polychromatic) at single or multiple wavebands. Since scattering profiles are influenced by density, cell structures and chemical composition of the fruit, they can be related to fruit firmness and/or soluble solids content. Spectral scattering prediction of fruit firmness showed good correlation $(r \sim 0.90)$ with Magness-Taylor firmness measurement, the standard destructive penetration test (Peng and Lu, 2007; Qing et al., 2007). The technique is noncontact, fast and relatively easy to implement; moreover, it could be used for simultaneous assessment of fruit firmness and soluble solids content. However, the technique, like NIR spectroscopy which captures spectral information, relies on calibration models to predict fruit firmness and/or soluble solids content. In addition, fruit shape and size need to be considered for better characterization of spectral scattering features.

Hyperspectral imaging integrates the main features of imaging and spectroscopy to acquire both spectral and spatial information from the product simultaneously, thus making it especially suitable and much more powerful for inspecting horticultural and food products, whose properties and characteristics often vary spatially (Kim et al., 2001; Gowen et al., 2007). Hyperspectral imaging is commonly implemented in one of the two sensing modes: pushbroom or line scanning mode and filter-based imaging mode ( $\mathrm{Lu}$ and Chen, 1998). In-line scanning mode, the imaging system line scans the moving product items, from which three-dimensional (3D) hyperspectral images, also called hypercubes, are created. In filter-based imaging mode, spectral images are acquired from the stationary product items for a sequence of wavebands using either liquid crystal tunable filter (LCTF) or acousto-optic tunable filter (AOTF). Line scanning mode is most commonly used because it is relatively easy to implement, especially when real-time, online applications are needed. Filter-based hyperspectral imaging systems require more complicated calibration and are not suitable for online applications. A hyperspectral imaging system needs a high performance digital camera covering the spectral region of interest and having a large dynamic range (12-bit or higher is preferred), low noise level (with a cooling device to reduce the sensor's thermal noise), and good quantum efficiency. Moreover, an imaging spectrograph, which disperses line images into different wavelengths, is an essential component for a line scanning hyperspectral imaging system; it should have an appropriate optical resolution and spectral response efficiency with minimal aberrations. In addition, it is critical to have an appropriate DC-regulated light source that is highly stable, with smooth spectral response. Those who have sufficient knowledge and experience in optics and imaging may use off-shelf optical components to assemble a hyperspectral imaging system to achieve cost savings and meet their specific application needs in the laboratory. However, most users would be better off by purchasing a turn-key hyperspectral imaging unit from a commercial company (e.g., Headwall Photonics Inc. and Themis Vision Systems in U.S. and Specim in Finland).

Hyperspectral imaging technology was used for measuring fruit maturity, firmness and soluble solids content (ElMasry et al., 2007; Lu and Peng, 2007; Noh et al., 2007), and for detecting bruises and bitter pits on apple and mushroom (Nicolaï et al., 2006; Gowen et al., 2008) deterioration in mushroom (Taghizadeh et al., 2010) and chilling injury and internal defect of cucumber (Cheng et al., 2004; Ariana and Lu, 2010). A spatially resolved technique based on hyperspectral imaging was developed for measuring the spectral absorption and scattering properties of horticultural and food products (Qin and Lu, 2008). Because of its ability to acquire a large amount of spatial and spectral information, hyperspectral imaging will find more and more applications in quality and also safety inspection of horticultural and food products in the coming decade. However, two major issues need to be addressed in application of the technology. First, hyperspectral imaging acquires spectral images at contiguous wavelengths and considerable redundancy exists in the hyperspectral image data. Therefore an effective algorithm is needed to reduce the data dimensionality and identify most useful features with fewer wavebands. While many generic application algorithms have been developed for this purpose, it is important that the users choose an appropriate one that would meet their application needs. Second, up to now, speed and time needed to acquire and process a huge amount of image data has 
been the impediment to real-time, online application of the technology. However, as the sensor and computer technologies are evolving rapidly, it is now feasible to implement hyperspectral imaging technology for fast, online sorting and grading of horticultural and food products (Chao et al., 2008; Ariana and Lu, 2010; Herrero-Langreo, 2010). This opens a new horizon for effective applications of the technology for inspection of different quality factors of horticultural products. The expected accuracy in dedicated applications (of what???) is, based on present experiments, 80-90\% correct classifications at least. Hyperspectral imaging can be adapted and/or simplified to the use of indexes based on a small number of wavelengths, thus improving industrial feasibility.

\subsection{Fluorescence spectroscopy}

Fluorescence spectroscopy measures the light of longer wavelengths emitted from the object after it is excited with a beam of light of short wavelengths (usually in the ultra-violet region). For the last 20 years, laser-induced fluorescence has been used for vegetative studies, such as to monitor stress levels and physiological states in plants (Belasque et al., 2008). Two types of fluorescence: (i) blue-green fluorescence in about $400-600 \mathrm{~nm}$ range, and (ii) chlorophyll fluorescence in about $650-800 \mathrm{~nm}$ range, are produced by green leaves. Fluorescence spectroscopy has been used to monitor nutrient deficiencies, stress and diseases in plants, in laboratory or field conditions. Application of this technology to industrial processes is yet to be fully developed.

\subsection{X-rays}

X-rays cover the spectral range of $0.01-10 \mathrm{~nm}$, which falls between gamma rays and ultra-violet rays. X-rays can penetrate through most horticultural products and the level of X-ray energy transmitted through the product depends on the incident energy and absorption coefficient, density and thickness of the product. X-ray imaging is thus useful for evaluating quality/maturity and internal defect of horticultural products. Various X-ray imaging technologies are available; they include X-ray radiography which scans layers of the product to create two-dimensional (2D) images and computed tomography or CT scanning which creates 3D images. X-ray imaging showed potential for evaluating the maturity of peach, mango, and lettuce (Brecht et al., 1991; Barcelon et al., 1999a,b). Physiological disorder in the plant tissues and the presence of insects or foreign objects often cause changes in the density and water content of the product. Hence, X-ray imaging is particularly useful for detecting various types of internal defects or foreign objects in horticultural products such as watercore and internal browning in apple, translucence in pineapple, freeze damage and dry sections in orange and tangerine, pits or pit fragments in tart cherry and peach, and the presence of insects in fruit (Tollner et al., 1992; Peiris et al., 1998; Shahin et al., 1999; Lammertyn et al., 2003a,b; Velasco and Medina, 2004; Hansen et al., 2005; Haff et al., 2006).

\subsection{Other vision technologies}

Several emerging vision technologies such as near-infrared (NIR) tomography and terahertz imaging have recently received considerable attention in medical diagnosis and non-destructive evaluation of non-food products (Gibson et al., 2005; Pickwell and Wallace, 2006; Kemsley et al., 2008). NIR tomography provides images for the interior of an object. As NIR light (usually in the range of 750-1300 nm) is injected into a turbid biological object, its attenuation and scattering is tracked by multiple sensors positioned at different locations from the incident point, and 2D or 3D images are constructed by using inverse algorithms to solve an appropriate dif- fusion theory model. However, since light scattering is dominant in the region of $700-1300 \mathrm{~nm}$, it presents considerable technological challenges in obtaining high resolution images.

Terahertz imaging technology represents another new frontier for non-destructive evaluation of food and biological materials (Pickwell and Wallace, 2006). Terahertz radiation refers to the spectral region of $0.1-3 \mathrm{~mm}$, falling between the far infrared and microwaves. Terahertz rays correspond to the energy level of molecular rotations and vibrations of DNA and protein, and hence they may provide spectral fingerprints for biological tissues. Terahertz wavelengths are sensitive to water and the technique can thus be useful for assessing tissue condition. The technology is still in an early development stage, but it could present some interesting opportunities in quality evaluation of horticultural products.

Thermal imaging (TI) is another emerging technique for noninvasive analysis in the food industry. Recent advances and potential applications for TI for food safety and quality have been reviewed (Gowen et al., 2010). Temperature mapping, measuring infrared radiation (long wave greater than $8 \mu \mathrm{m}$ ) emitted by the body surface, where temporal and spatial distribution patterns are obtained, shows potential for food product quality and safety monitoring. While applications are reported for apple, tomato (detection of bruises), potato (freezing damage) and citrus (drying time), the technology is still in experimental stage.

\section{Nuclear magnetic resonance (NMR) spectroscopy and imaging}

Since the discovery of the magnetic resonance phenomenon in 1946 and subsequent achievements, nuclear magnetic resonance (NMR) has become one of the most significant non-invasive techniques for internal inspection of biological objects (see Table 1). Derived from NMR are NMR spectroscopy, NMR relaxometry and magnetic resonance imaging (MRI). For NMR spectroscopy resonance frequency encodes the chemically equivalent nuclei populations at different electronic and chemical environments so that the outcome is an NMR spectrum where intensity is plotted versus frequency. MRI devoted spatial codification of the signal intensity produces a two- or three-dimensional image. NMR relaxometry identifies nuclei populations distinguishable due to the different signal decay time constants, that is, relaxation times. NMR technique offers information about the inside of an object, thus making it feasible for quality classification of fruits and vegetables. NMR is a useful non-destructive monitoring technique for a wide range of applications because it is sensitive to the concentration, chemical environment, mobility, and diffusion among other phenomena, related to certain nuclei. These phenomena are influenced by cell compartmentation and tissue microstructure so that the NMR signal also acts as sensor of the tissue integrity. A number of review articles and books on applications of NMR for quality evaluation of fruits and vegetables have been published recently (Hills and Clark, 2003; Aristizábal, 2007; Hernández-Sánchez et al., 2009). The first reported applications focused on quantification of main components such as water and fat content by NMR spectroscopy. Subsequent studies performed more complex analysis based on NMR relaxometry. MR images allow internal tomography where tissue contrast mainly arises from differences in relaxation times and proton density, and are also used for characterization.

\subsection{Stationary examination}

Studies that have been conducted in fruits and vegetables with NMR techniques mainly relate to the maturity and ripeness, internal damage and defect, and physiological disorders appearing during storage and caused by pre- and postharvest conditions (Hills 
Table 1

Summary of quality attributes and disorders in fruits and vegetables studied by NMR relaxometry (MRR), NMR spectroscopy (MRS) and MRI techniques (including proton density (PD) maps).

\begin{tabular}{|c|c|c|c|c|c|c|}
\hline Product & Maturity/sugar content & Bruises/voids/seeds & Tissue breakdown & Heat injury & Chill/freeze injury & Infections \\
\hline \multicolumn{7}{|l|}{ Fruit } \\
\hline Apple & MRR/MRI & MRI & MRI/MRR PD maps & & & \\
\hline Avocado & MRS/MRI & & & & & \\
\hline Banana & MRR & & & & & \\
\hline Cherimoya & MRR/MRI & & & & & \\
\hline Durian & MRS/MRI & & MRI & & & \\
\hline Kiwifruit & MRR & & & & MRI/MRR & MRI \\
\hline Mandarin & MRR PD maps & MRI & & & & \\
\hline Mango & MRS/MRR & & & MRI & & MRI \\
\hline Mangosteen & MRI & & & & & MRI \\
\hline Melon & MRS & MRI & MRI & & & \\
\hline Nectarine & & & MRI & & & MRR PD maps \\
\hline Orange & MRS/MRR & MRI & & & MRI & \\
\hline Papaya & & & & MRR & & \\
\hline Peach & & MRI & & & MRR/MRI & \\
\hline Pear & & MRI & MRR/MRI & & & \\
\hline Persimmon & & & & & MRI & \\
\hline Pineapple & MRR/MRI & & & & & \\
\hline Tangerine & MRI & MRI & MRI & & & \\
\hline Watermelon & MRS & MRI & & & & \\
\hline \multicolumn{7}{|l|}{ Berries } \\
\hline Blueberry & MRI & & & & MRI & \\
\hline Grape & MRS/MRR & & & & & \\
\hline Strawberry & & & & & & MRI \\
\hline \multicolumn{7}{|l|}{ Small, stone fruits (drupes) } \\
\hline Cherry & MRR/MRS & MRI & & & & \\
\hline Olive & MRI & MRI & & & & \\
\hline Plum/prunes & MRS & & & & & \\
\hline \multicolumn{7}{|l|}{ Vegetables } \\
\hline Courgette/Zucchini & & & & & MRI & \\
\hline Cucumber & & & & & MRI & MRI \\
\hline Onion & & MRI & & & & \\
\hline Potato & MRR/MRI & MRI & MRI & & & MRI \\
\hline Tomato & MRR/MRI & & & & & \\
\hline
\end{tabular}

and Clark, 2003; Aristizábal, 2007). NMR spectroscopy and MRI are used to monitor air spaces shrinkage and NMR relaxometry are recently reported to detect decreasing relaxation times with ripeness (Musse et al., 2009). $\mathrm{T}_{2}$ times and relaxation times were used to estimate tomato firmness with negative results (Tu et al., 2007), and the ripening of kiwi (Hills and Clark, 2003), banana (Raffo et al., 2005) and cherimoya (Goni et al., 2007). In persimmon $\mathrm{T}_{1}$ declined abruptly during ripening whereas $\mathrm{T}_{2}$ increased smoothly (Clark and MacFall, 2003). Further positive results are published on apple and on pear related to sugar content and firmness, both based on analysis of $\mathrm{T}_{2}$-weigthed MR images (Hills and Clark, 2003; Aristizábal, 2007). Water suppression by diffusive attenuation was used in $\mathrm{T}_{1}$ measurements to successfully measure Brix in intact cellular tissue of apple and strawberry (Marigheto et al., 2006), and oil content in avocado (Marigheto et al., 2005), and many other products (Aristizábal, 2007), which should be useful for rapid, online measurements.

Among different types of internal defect, insect damage, fungal infection, bruise, and the presence of seeds or pits have been major issues. Larvae cavities were observed in MR images for pear, mango and peach (Aristizábal, 2007). Fungus infection has been inspected using MRI in nectarine, strawberry, grape, mandarin, orange and coconut (Hills and Clark, 2003; Aristizábal, 2007). MRI has also provided contrasted images for the inspection of bruises in apples, peaches, pears, onions, strawberry guava and potato (Aristizábal, 2007). Multivariate image analysis of MR images of tomato proved to be effective for predicting the conductivity score of pericarp tissue in tomatoes for bruises detection (Milczarek et al., 2009). The presence of seeds or pits was inspected with MRI in a number of products such as plum, cucumber, peach and olive, cherry, mandarin and orange (Kim et al., 2008; Hernández-Sánchez et al., 2009). For cherries and olives one-dimensional MR images (projections) sufficed (Hills and Clark, 2003) due to the large proportion of volume occupied by the pit within the fruit whereas for the other products two-dimensional MR images were required for detection in order to avoid partial volume effect (Hernández-Sánchez, 2006).

Physiological disorders have also been of great interest. Among those developed during the pre-harvest period works have mainly focused on freezing damage and watercore. Aristizábal (2007) cited an early work where dehydrated vesicles were detected in MR images of oranges affected by freezing damage. Early works showed the viability of detecting freezing injuries in products such as blueberries, kiwifruit, persimmons and peaches by means of contrast changes in MR images, and in apple tissue through MR relaxometry (reviewed by Hills and Clark, 2003). Damaged areas present a reduction of the proton density and the relaxation constant $T_{2}$ (Gambhir et al., 2005), which are the source of the contrast in the MR images. The percentage of damaged tissue was addressed in static and dynamic MR images obtained from oranges on the tree that had been exposed at freezing temperatures (HernandezSanchez et al., 2004). Dehydrated tissue and cavities were also observed by Aristizabal Torres (2006) in similar samples. Fast detection of seeds and freeze damage in mandarine citrus fruit was performed using MRI in a $1 \mathrm{~T}$ industrial grade permanent magnet (Kim et al., 2008). Detection of watercore in apples was feasible because the reduction of the proton density and the relaxation times in affected tissue involve intensity contrast in the MR images (Hills and Clark, 2003; Marigheto et al., 2005). The postharvest disorders appearing during storage that have been thoroughly inspected with NMR techniques are internal browning and internal breakdown, mealiness and wolliness, core breakdown in apples, peaches and pears (Lammertyn et al., 2003c; Hernandez-Sanchez et al., 2007; Cho et al., 2008; Marigheto et al., 2008). 
Most of the aforementioned works have been undertaken with commercial NMR equipment designed for medical purposes. Such equipment operate at high magnetic field strength of more than $2 \mathrm{~T}$ with high performance and expensive hardware requiring high initial capital investments. In addition, they are difficult to implement in an industrial environment. Hills and Clark (2003) and Hills (2006) suggested that the field homogeneity within large volumes in low-field equipment and the compatibility with commercial fruit graders should be major subjects for advancing the technology into industrial applications.

\subsection{Moving measurements}

Industrial implementation of NMR techniques for internal inspection requires satisfactory performance under motion conditions. This issue has been studied in recent works (Hills and Wright, 2006).

For pit detection in cherries and olives, MR projections were acquired with a 2 T NMR spectrometer (reviewed by Hills and Clark, 2003) while samples were conveyed at belt speeds ranging from 0 up to $250 \mathrm{~mm} / \mathrm{s}$. Classification errors were greatly affected by sample orientation. In detecting maturity in avocados (reviewed by Hills and Clark, 2003) MR spectra were analyzed. The conveyor speed varied from 0 to $250 \mathrm{~mm} / \mathrm{s}$ and the fruit were placed at different orientations with respect to the radio-frequency coil. The researchers found high correlation with dry weight (from 0.894 to 0.975 ) as the motion of the sample had small effect on the acquired signal when single-shot sequences are used. A real-time, in-line NMR quality evaluation sensor was designed, constructed and tested for several fruits to acquire NMR signals when a sample is within $\pm 50 \mathrm{~mm}$ of the NMR coil center at speeds ranging from 0 to $300 \mathrm{~mm} / \mathrm{s}$ (Kim and McCarthy, 2006). Detection of freeze injury in citrus under motion conditions (Hernandez-Sanchez et al., 2004) was evaluated using an NMR spectrometer of 4.7 T. Fast Low Angle Shot (FLASH) images were obtained as oranges were conveyed at 50 , and $100 \mathrm{~mm} / \mathrm{s}$ belt speeds. Image blurring was induced by the excitation of consecutive slices driven by the axial location of the field of view (FOV). For seed identification in citrus (HernandezSanchez et al., 2006) the re-orientation of the FOV from axial to coronal images solved the problem of signal superimposition, and necessitated the development of devoted algorithms to correct phase shift induced by sample motion. The features extracted automatically from the motion-corrected images were not significantly different from those extracted from the static ones. FLASH images and combined spiral radial (COMSPIRA) images were obtained from seedless and seed-containing mandarins while conveyed at $50 \mathrm{~mm} / \mathrm{s}$. Phase shift correction was applied for image reconstruction prior to image analysis. The seed identification was up to $100 \%$ accuracy using COMSPIRA images and image postprocessing based on the variance of 2D histograms (Barreiro et al., 2008). Results have yet to be validated at low-magnetic field strengths and higher conveyor speeds. A $1 \mathrm{~T}$ industrial grade permanent magnet was used to acquire MR images in mandarines and threshold-based image analysis has proven successful in detecting seeds and quantifying freeze damage (Kim et al., 2008). For inspection of internal breakdown in pears coronal FLASH images were acquired from the equatorial slice of pears conveyed at about $50 \mathrm{~mm} / \mathrm{s}$ through a $4.7 \mathrm{~T}$ magnet (Hernandez-Sanchez et al., 2007). Correct classification was $98.4 \%$ although the final performance remains to be validated at low-magnetic field strengths and higher conveyor speeds. Internal browning in apples was inspected with a lowcost, low-field instrument of 0.13 T (Chayaprasert and Stroshine, 2005) obtaining $T_{2}$ global measurements at different belt speeds up to $250 \mathrm{~mm} / \mathrm{s}$. Encouraging results were obtained at $50 \mathrm{~mm} / \mathrm{s}$ with a classification error of $12 \%$ although performance decreased at higher speeds.
To date, none of these technologies have been implemented in the industry. Hernández-Sánchez et al. (2009) state that such technology transfer would require closer and more active interactions between researchers and the food industry, in order to develop reliable and cost-effective NMR equipment with the capacity to meet industrial application needs.

\section{Computer vision for external quality and defects}

Kader (2001) classified the quality attributes of fresh horticultural produce in four groups: appearance, texture, flavor, and nutritional factors. Appearance traits include size or dimension, shape, surface texture, surface color, and external or surface defects. Appearance factors define external quality and directly influence consumers in purchasing a product, and they can be evaluated by means of computer vision techniques. For some authors (Brosnan and Sun, 2004) the terms computer vision and machine vision are synonymous, whereas for others (Graves and Batchelor, 2003) computer vision is a science. Computer vision systems measure the reflectance of an object but also the distance (range) to the object. While reflectance data are only necessary for color assessment and external defects identification and quantification, size, shape and surface texture can be evaluated either from reflectance or from range data.

As in human vision, computer vision is highly dependent on by the level and quality of illumination, regarding spectrum, stability and spacial distribution. Two key parameters in any computer vision system are spatial resolution and dynamic range. Resolution is the ability to spatially resolve details in an image, while dynamic range refers to the range of light levels that can be captured by the imaging device. The image sensors used in computer vision are based on solid state charge-coupled device (CCD) or complementary metal-oxide semiconductor (CMOS) technology. There are also some applications using vidicon tubes and charge injection device (CID). CID sensors are the preferred option when high reflections are an issue, because CCDs are easy to saturate under these conditions. An alternative way to overcome when specular reflection, while sensing with a CCD, is to use polarizing filters. Both CCD and CMOS sensors are available in area-scan, line-scan version. Most cameras used in commercial fruit sorting systems are equipped with area-scan sensors, also known as matrix or array sensors.

\subsection{Size and shape}

Although computer vision-based determination of axes or diameters, projected area and circumference is considered a solved issue, accurate fruit volume measurement at high speed has only become available in the last few years (Moreda et al., 2009). Accurate volume determination is of interest for online electronic density sorting. Fruit density sorting is useful because there are products like grapes or kiwifruit whose density is correlated to compositions such as soluble solids (Sugiura et al., 2001; Jordan and Clark, 2004). Furthermore, density determination is of interest for separating freeze-damaged citrus fruits (Miller et al., 2006), puffy tangerines (Aleixos, 1999), fruits with internal damage caused by insects (Forbes and Tattersfield, 1999), watermelons with a high degree of hollowness (Kato, 1997), and apples with watercore. The typical accuracy of $1 \mathrm{~mm}$ offered by machine vision equipment manufacturers suffices for the sizing of most fruits and vegetables based on fruit axes or diameters. However, commercial vision systems that compute volume from 2D images generally do not yield high precision volume measurements required for density sorting. Nowadays, 3D machine vision systems are being introduced in some food industries (Montrose Technologies; SICK-AG, 2010), and this trend could be further expanded into the fresh produce industry, where 3D cameras could be used, besides for 
accurate volume measurement, for shape sorting and surface area quantification.

Fruit shape is one of the most important factors for classifying and grading fresh horticultural produce, but in many packinghouses fruit shape is still manually determined (Xiaobo et al., 2008). Fruit shape determination is of interest for several commercial reasons, including elimination of ill-shaped fruits and fruit damages which are located on non-flat fruit surfaces (Hryniewicz et al., 2005). Moreover, misshapen fruits such as pear-shaped grapefruit are often considered defective (Syvertsen et al., 2005). For some commodities like banana, mango, broccoli or cauliflower, shape is used as a maturity index (Studman, 2001).

Automated shape determination techniques can be classified into two categories: 2D and 3D. Two-dimensional methods analyze the shape of a planar digital image of the object taken by a video camera, whereas 3D approaches try to reconstruct the object's 3D surface. Few works have dealt with online 3D shape inspection for specialty crops, and most of the research reported so far has relied on digital planar images. Noordam (2010) used six lasercameras to construct the 3D shape of sweet pepper fruits, based on triangulation. Two-dimensional shape features can be measured independently or by combination of size measurements (Du and Sun, 2004). Circularity, aspect ratio and compactness are examples of simple mathematical combinations of size measurements. More sophisticated shape analyses can be performed independent of size measurements; these can be classified (Zhang and Lu, 2004) into region-based (Heinemann et al., 1995) and contourbased (Abdullah et al., 2006; Menesatti et al., 2008; Jarimopas and Jaisin, 2008; Riyadi et al., 2008; Costa et al., 2009). Table 2 summarizes classification accuracies reported by several researchers using different shape description techniques. Among size-independent shape analysis techniques, contour-based techniques are generally more popular than region-based approaches. Region-based methods are more robust as they use all the shape information available. It should be mentioned that although high classification accuracies have been reported (Table 1), most of the works were undertaken off-line and/or under laboratory conditions.

The potential of imaging sensors for quality classification of potted plants under greenhouse production has been explored recently. Commercial protected glasshouse crop environments allow many important environmental factors (e.g., lighting and temperature) to be partly or totally controlled during growth (Parsons et al., 2009). It is, however, difficult to assess ornamental quality because only subjective references can be used. Feedforward artificial neural networks were used to segment top and side view images of three contrasting species of bedding plants. The segmented images provided objective measurements of leaf and flower cover, color, uniformity and leaf canopy height. The extracted image features would explain $88.5 \%, 81.7 \%$ and $70.4 \%$ of the panel quality score. Prediction models based on artificial neural networks cannot achieve high accuracy, and most of them have poor capabilities for systematic improvement and low robustness.

\subsection{Surface texture}

Surface texture refers to the topographic or relief features on the outermost boundary of an agricultural product. Typical examples include the wrinkles on prunes and raisins and the rough or pebbly surface of an orange. Surface texture is a quality parameter in many fruits. For example, high quality raisins are categorized by fine wrinkles. Fekete and Olasz (2005) monitored the senescence of apples kept in a cold room by analyzing fruit surface wrinkles. In some commodities, maturity is partly defined by surface texture. Surface texture is difficult to measure, because it is a true 3D measurement. Triangulation laser range finding, often abbreviated as 'laser scanning' (although 'laser scanning' is misleading, since it

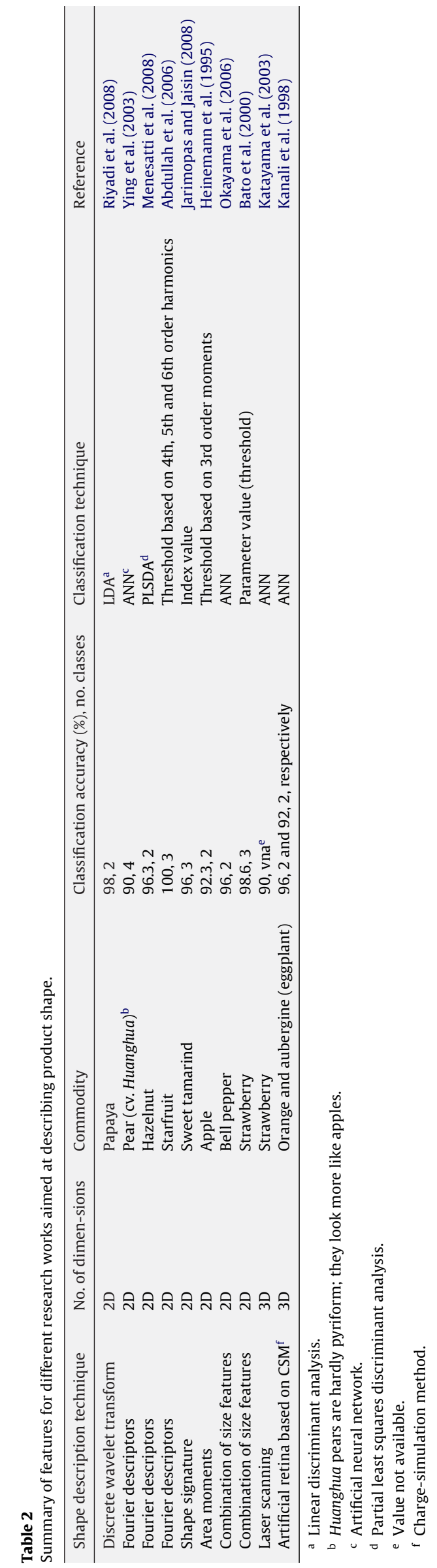


also accounts for time-of-flight laser range finding), is a well-known method used to measure surface features of manufactured goods, which could be used in fruit surface texture analysis. A more popular approach for produce surface texture inspection is the use of 2D computer vision. Dunn (2007) developed image analysis algorithms to classify citrus fruits according to peel roughness by analyzing planar images. The experimental setup consisted of a source of light, the fruit (orange) and a video camera, arranged horizontally at the vertices of a right-angled triangle, so that the image acquired by the camera was a sort of 'half-moon'. With this setup, the ragged 'terminator' line separating the lit and shadow zones of the orange surface was frequency and amplitude analyzed. In this concept, if the object is a billiard ball instead of a citrus fruit, the 'terminator' line would be straight instead of ragged. A strong correlation between the computer vision measurements and the subjective visual rankings was reported, but the results were not quantified or validated.

Other potential techniques for surface texture analysis are stereovision, moiré interferometry, holographic interferometry, and Fresnel diffraction. Holographic interferometry allows very high spatial discrimination in the order of $10^{-10} \mathrm{~m}$, but the technique currently is too expensive to be practical for specialty crops.

\subsection{Surface color}

Color is a human perception by definition, which has long been used in the assessment of fruit quality. In fruits, a decrease in chlorophyll content of the skin is correlated with increasing maturity; this is traditionally used as the criterion for visual assessment of fruit maturity (Crisosto et al., 2007). Some fruits have one color homogeneously distributed on the skin surface, and the averaged surface color is a good quality indicator for these fruits. In the early years of application of computer vision to fruit inspection, fruit color assessment relied on grey-scale images captured by monochrome cameras, for instance, for classification of bell pepper or oranges in color classes. This approach is only applicable when the product is mono-colored, and defect detection is not required. Other fruits, like some cultivars of peaches and apples, have a secondary color that is frequently used as an indicator of maturity, which often is not reliable.

Produce color sorting in modern packinghouses is performed using RGB color video-cameras. Each pixel in a color image consists of three intensity values, since any color can be reproduced by the combination of three primary color components: blue, green, and red. Each of these components: R, G and B, covers a large part of the visible spectrum, as compared to multispectral cameras that use narrow bands. The techniques require previous and also continuous training to adapt the system to the great color variability present in products like fruits (Blasco et al., 2007; Lleo et al., 2009). In general, online fruit color grading by means of computer vision is considered solved and is widely used now by the industry. However, color sorting is not suitable for measuring or assessing internal quality, which may require multi- and hyperspectral imaging as discussed above.

Image color accuracy and spatial resolution have been greatly improved in three-chip (CCD, CMOS) cameras (Pitre et al., 2010). Three-chip color cameras use dichroic prisms to direct the light in each of the three wavebands. Single-chip color cameras, with substantially increased resolution without diminishing sensor sensitivity and dynamic range, were recently developed (DigitalPhotography-Review, 2008).

\subsection{External or surface defects}

Blemish sorting has been addressed together with color sorting for many years mainly because many defects exhibit special color characteristics. For instance, apple skin affected with rus- seting is brown, and severe fungal attacks in orange are shown as a greenish or whitish peel. In fact, human inspectors in packinghouses depend heavily on color to differentiate defects. Xing et al. (2007) stated that although computer vision systems have received much attention for sorting apples, oranges, peaches and other fruits into different categories according to size and color, they still have some limitations in surface defect detection. Blemishes are difficult to detect when their color coincides with the color of the sound peel. Recent techniques use multispectral (Aleixos et al., 2002), or hyperspectral imaging (Tallada et al., 2006; Kim et al., 2007) to detect blemishes. Guyer and Yang (2000) used artificial neural networks and spectral imaging for identification and quantification of different types of cherry surface defects, like dry crack, wet crack, mold, and bruise. An average of $73 \%$ classification accuracy was achieved for correct identification as well as for quantification of different types of cherry defects. No false positives or false negatives occurred; errors resulted only from misclassification of different types of blemishes or the quantification of the size or number of defect. Tallada et al. (2006) took spectral images from strawberries in the range from 650 to $1000 \mathrm{~nm}$ at $5 \mathrm{~nm}$ intervals to determine two optimal wavebands for the detection of bruises. Optimal wavebands of $825 \mathrm{~nm}$ and $980 \mathrm{~nm}$ were obtained using stepwise linear discriminant analysis. The non-bruised samples were perfectly classified as non-bruised, i.e., there was no false-positive classification. Bruised samples with larger damage (applied in the laboratory) were perfectly classified, while variations in the accuracies for small bruises were observed, and they depended on degree of ripeness. Kim et al. (2007), using a NIR twoband reflectance ratio coupled with a simple classification method based on the mean intensity and homogeneity of the ratio, achieved a $99.5 \%$ apple defect classification.

The detection of skin defects is closely related to the ability to correctly identify the stem cavity or the calyx. The 'stem/calyx issue' has been tackled through different approaches: mechanical orientation, 2D image processing, 3D shape capturing, and logical comparison of images corresponding to different wavelengths, and is already present in commercial fruit handling equipment. Throop et al. (2005) described a handling system that oriented several apple cultivars with a success rate higher than $97.6 \%$. When the $3 \mathrm{D}$ shape of the fruit is reconstructed, the problem of mistaking the stem cavity for a blemish disappears. Yang (1996) recovered the 3D shape of apples by projecting structured light on the fruit surface, the shape-from-shading technique to construct the 3D surface of apples from 2D NIR images; they report a 90.1\% defect detection at a throughput of 1 fruit per second. Wen and Tao (2000) used a dual-camera system comprised of a visible-NIR camera and a mid-infrared (MIR) camera. The NIR camera detected both defects and concavities, whereas the MIR camera detected only concavities. Defect detection was achieved by logical comparison of the images delivered by the two cameras. Finally, the above-mentioned NIR processing regime of the work by Kim et al. (2007) overcame the presence of stem/calyx on apples. More recently, 3D reconstruction using a shape-from-shading approach was combined with a quadratic facet model to reconstruct the 3D concave shape (Jiang et al., 2009).

\section{NIR and IR spectroscopy}

Different NIR and IR spectroscopic techniques currently are being used for specialty crops. Table 3 summarizes some relevant applications published in the past two decades.

\subsection{NIR spectroscopy}

According to the IUPAC definition (Sheppard et al., 1985), NIR radiation covers the range of the electromagnetic spectrum 
Table 3

Relevant applications of NIR- MIR spectroscopy in specialty crops.

\begin{tabular}{|c|c|c|}
\hline Category & Subject & Reference \\
\hline \multirow{10}{*}{ NIR } & Dry matter content of onions & Birth et al. (1985) \\
\hline & Soluble solids content of apples & Bellon-Maurel (1992) \\
\hline & Water content of mushrooms & Roy et al. (1993) \\
\hline & Acidity, soluble solids, and firmness of apples & Lammertyn et al. (1998) \\
\hline & Detection of brown heart in apples & Clark et al. (2003) \\
\hline & Prediction of the sensory quality attributes of apples & Mehinagic et al. (2004) \\
\hline & Prediction sensory attributes of chicory & François et al. (2008) \\
\hline & SRS for measuring the sugar content and firmness of apples & Peng and Lu (2007) \\
\hline & Estimation of water and chlorophyll content & Cubeddu et al. (2001) \\
\hline & TRS for modeling nectarine softening & Zerbini et al. (2006) \\
\hline \multirow{4}{*}{ MIR } & ATR-FTIR for detecting sugars and acids in tomatoes & Beullens et al. (2006) \\
\hline & ATR-FTIR for detecting sugars and acids in apples & Rudnitskaya et al. (2006) \\
\hline & Detection of changes in macromolecular constituents of hazelnut & Dogan et al. (2007) \\
\hline & Quantification of olive oil acidity & Inon et al. (2003) \\
\hline
\end{tabular}

between 780 and $2500 \mathrm{~nm}$. In NIR spectroscopy, the product is irradiated with NIR radiation, and the spectrum of the reflected or transmitted radiation is measured. The spectral characteristics of the incident ray are modified while it passes through the product due to wavelength dependent absorption and scattering processes. This change depends on both the chemical composition and the physical properties of the product (Nicolai et al., 2007). Advanced multivariate statistical techniques such as partial least squares regression (PLS) are then applied to correlate the NIR spectrum to quality attributes such as the sugar content or firmness of the product. This relation can be used to calculate the quality attributes of future samples from their NIR spectrum.

NIR spectroscopy has been used for rapid analysis of mainly the moisture, protein and fat content of a wide variety of agricultural and food products (Gunasekaran and Irudayaraj, 2001; Butz et al., 2005). While early applications in horticulture focused on the dry matter content of onions (Birth et al., 1985), the soluble solids content (SSC) of apples (Bellon-Maurel, 1992) and the water content of mushrooms (Roy et al., 1993), many other applications have followed. As the propagation of NIR radiation in fruit and vegetable tissue is affected by its physical properties and notably its microstructure, NIR spectroscopy has also been used to measure microstructure related attributes such as stiffness (Lammertyn et al., 1998), internal damage (Clark et al., 2003), and even sensory attributes (Mehinagic et al., 2004; François et al., 2008). A comprehensive overview of applications of NIR spectroscopy to measure quality attributes of fruit and vegetables was recently published (Nicolai et al., 2007). It includes a comprehensive table with the most relevant and recent applications, up to 2007. A very large number of papers have been published in recent years concerning NIR spectroscopy in foods, and specialty crops are one of the beneficiaries, and the most recent papers usually contain good reviews on the matter (Liu et al., 2010).

The information related to the physical (scattering) and chemical (absorption) properties of the biological tissue is combined within the NIR spectrum. Both space-resolved and time-resolved techniques have been used to separate the scattering and absorption information. In space-resolved spectroscopy (SRS), a camera is used to acquire a hyperspectral image of a spot of light which is projected on the surface of the fruit. The size of the reflected spot is larger than the projection area because of scattering, and may depend on the wavelength. The hyperspectral image can then be correlated to the quality attributes of the product. This technique has been used with good result for measuring the sugar content and firmness of apple fruit (Peng and Lu, 2007). In time domain reflectance spectroscopy (TRS), series of very short (picosecond or femtosecond) NIR light pulses are illuminated into the fruit using a tunable laser or a solid state laser array (Cubeddu et al., 2001). The detector is positioned at some distance from the light entry point of the incident photons. Depending on the scattering properties of the tissue, the photons may follow a complicated path in the tissue and it may take more or less time to reach the detector. As a result, the detector will measure a photon time-of-flight distribution from which, based on light diffusion theory, the absorption and scattering coefficient as a function of wavelength can be measured. These coefficient spectra can then be correlated with internal quality attributes. So far the obtained correlations between absorption and scattering spectra and quality attributes such as SSC or firmness were low (Valero et al., 2004; Zerbini et al., 2006) to non-existent (Nicolai et al., 2007), most probably due to instrument drift or the limited wavelength range $(\leq 1030 \mathrm{~nm})$ considered in the experiments. In the same context as TRS and SRS there is recently an increasing interest towards calibration techniques which rely on the actual physics of penetration of NIR radiation in fruit tissue rather than on a pure statistical analysis such as PLS on empirically preprocessed spectra. Advanced light transport simulation models based on the diffusion approximation, the adding-doubling method or the Monte Carlo method might guide these research efforts, and make it possible to separate the information related to the physical (scattering) and chemical (absorption) properties of the biological tissue (Saeys et al., 2008).

Most applications of NIR spectroscopy which are described in the literature essentially rely on spot measurements. The availability of affordable hyperspectral cameras and spectrographs has provided exciting new possibilities for online defect detection which are not feasible with visible light, such as detection of defects which are difficult to observe in the visual range of the spectrum such as early bruises in apple fruit (Xing and De Baerdemaeker, 2005). While acquisition speed is still an issue, focal plane array cameras may solve this problem. NIR microscopes implementing this technology have appeared recently, and it is expected that they will provide a better understanding of the microscopic distribution of, e.g., sugars or other interesting biochemical components at the histological or cellular level.

The availability of fast and relatively cheap diode array spectrometers which allow to acquire an NIR spectrum in as little as $50 \mathrm{~ms}$ has boosted research and development towards commercial applications, and grading lines equipped with NIR sensors are now commercially available from different manufacturers. More widespread use of this technology depends on several factors, of which model robustness is the most important technical one. Obviously, the accuracy of the NIR calibration models should be sufficient even when they are used to predict quality attributes of product specimen which were not used in the model calibration. Calibration models to be used in practice should be based on large datasets, encompassing several origins, climate conditions, seasons and operational conditions such as temperature, and optimised towards robustness by incorporating appropriate spectral prepro- 
cessing methods. Protocols are needed to update calibration models with minimal effort. Other issues which have to be considered are temperature sensitivity of NIR measurements (Roger et al., 2003) and transfer of a calibration model to a different spectrophotometer (Greensill et al., 2001).

\subsection{Mid-IR spectroscopy}

Mid-infrared spectroscopy addresses the interaction of matter and electromagnetic radiation with a wavelength between 2.5 and $25 \mu \mathrm{m}$. Absorption of Mid-IR light results from transitions between vibrational and rotational energy states of molecules. MidIR spectra are commonly acquired by means of Fourier Transform IR spectrometers (FTIR). The main advantage of Mid-IR in comparison to NIR spectroscopy is the fact that the Mid-IR spectrum is much less convoluted than the NIR spectrum; the peaks are much sharper and can often be directly associated with specific chemical constituents. However, an inherent problem in Mid-IR spectroscopy is the limited penetration depth. While for NIR radiation the penetration depth in biological tissue is of the orders of $\mathrm{cm}$ in the so-called optical window between 700 and $900 \mathrm{~nm}$, it rapidly decreases to $1 \mathrm{~mm}$ or less at $1600 \mathrm{~nm}$, and in the Mid-IR range it is only fractions of a millimeter (Lammertyn et al., 2000). FTIR spectroscopy is therefore mainly used to characterize homogeneous samples such as juices, often in combination with an attenuated total reflection (ATR) sample presentation accessory. ATR-FTIR has been used to detect sugars and acids in tomatoes (Beullens et al., 2006) and apples (Rudnitskaya et al., 2006), to detect changes in macromolecular constituents of hazelnut (Dogan et al., 2007), and to quantify olive oil acidity (Inon et al., 2003). Mid-IR spectroscopy seems to be more appropriate for qualitative (classification) purposes or to detect adulteration rather than for the quantitative measurement of quality attributes of agricultural products.

\subsection{Fluorescence and delayed-light emission (DLE)}

Fluorescence and phosphorescence are summarized by the term "photoluminescence". To activate a luminescence response in a body, excitation is accomplished by short-wavelength light, traditionally in the UV, but also in the VIS range. Most applications of fluorescence in plants that have been published are related to the determination of chlorophyll activity. DLE is fluorescence that develops shortly after excitation, due to intermediate reactions in photosynthesis (Butz et al., 2005).

Applications of fluorescence reported in the literature have been related to chlorophyll, as an indirect marker for fruits' physiological status: chlorophyll degrades in fruits, and also in vegetables, as a consequence of ripening, senescence, time and treatments. Butz et al. (2005) include references regarding applications in: freshness of broccoli, postharvest defects in apples, cold damage in oranges, and senescence in cucumber. Some chemicals in plants, different from chlorophyll, fluoresce, like phenolics. As fluorescence response is dependent on the excitation wavelengths and the response is also wavelength dependent, the technique shows a potential high specificity of the response of different compounds. Hyperspectral devices have been used to characterize fluorescence responses, e.g., for the characterization and differentiation of edible oils of plant origin using lasers as excitation source (Kim et al., 2001; Sikorska et al., 2005). Slaughter et al. (2008) used visual and machine-vision methods for early detection of frost damage in oranges. Fluorescence is a promising technique, widely used in chemistry, which could be the basis for new specialized sensors. However, substantial research is needed in the basic science of fluorescence to advance possible applications, as well as in the instrumentation and its applicability in practice.
Some publications show the applications of fluorescence imaging for detection of quality of fruits (Liu et al., 2008; Valcke, 2008) even integrating it with conventional reflectance (Noh et al., 2007). They use a laser as fluorescence-inducer, and hyperspectral imaging for capturing. More in-depth knowledge on the fluorescing agents of intact fruits is needed, and their relationship with fruit quality before feasible applications may be developed.

\section{Mechanical methods for firmness measurement}

Mechanical techniques have been developed to nondestructively measure some quality parameters of fruit and vegetables, mainly for firmness estimation, providing an alternative to the destructive Magness-Taylor penetrometry (García-Ramos et al., 2005; Nicolaï et al., 2006). Major mechanical techniques include the measurement of variables extracted from quasi-static force-deformation curves, the analysis of impact forces, and the measurement of acoustic responses to vibrations and impacts.

\subsection{Measuring the variables of force-deformation curves}

By applying a small deformation force to the fruit with a metallic plunger in such a way that it causes no damage, the non-destructive force-deformation curve can be recorded using an analogue (spring) or a piezoelectric sensor positioned at the back of the compression plunger. The curve is produced by applying a small load for a fixed period of time (Macnish et al., 1997) or by calculating the force necessary to reach a pre-set deformation (Fekete and Felföldi, 2000). This non-destructive technique (also known as micro-deformation) has led to the development of a number of force-deformation devices.

Micro-deformation sensor developed by Cemagref (French agricultural and environmental engineering research institute) (Steinmetz et al., 1996) consists of a flexible positioning cup with a contact plunger in the centre to slightly deform the fruit surface (maximum $2 \mathrm{~mm}$ approx.). A micro-deformation device was developed by Copa Technology in collaboration with CTIFL (Centre Techniques Interprofessionnel des Fruits et Légumes). Their "Durofel" instrument has a metallic, flat-ended probe with three possible contact areas $\left(10,25,50 \mathrm{~cm}^{2}\right)$, and is based on the Shore A durometer. The device has been widely used for apricots (Jay et al., 2000), tomatoes (Planton, 1991), cherries (Clayton et al., 1998) and other soft fruits.

Macnish et al. (1997) describe two non-destructive devices for measuring firmness developed by CSIRO (Australia's Commonwealth Scientific and Industrial Research Organization): the Analogue Firmness Meter (AFM) and the Digital Firmness Meter (DFM). These devices have been used with tomatoes and mangos. The fruit is placed in a v-shaped structure, and then a $40 \mathrm{~mm}$ diameter disc is applied to it. The disc is joined by an arm to an analogue displacement gauge (Macnish et al., 1997).

A non-spectroscopic method of measuring mechanical deformation with a laser has been developed (Hung et al., 1999). Known as the "laser air-puff", this device measures the deformation of fruits subjected to a short but strong current of air (69 kPa in $100 \mathrm{~ms})$. McGlone et al. (1999) used a similar system to test kiwifruit, but only very soft fruit could be accurately distinguished (McGlone et al., 1999). More recently, Lu and Tipper (2009) develop a portable bioyield detection device to measure apple fruit firmness, which measure force at the bioyield point as an indication of fruit firmness.

\subsection{Sensors based on force-versus-time measurements (impacts)}

There are many ways of using impact sensors, such as: (a) hitting the fruit with some element that includes the sensor; (b) putting 
the fruit over a load cell and letting a weight fall on it; (c) placing the fruit on a flat plate with a load cell located beneath it.

Chen and Ruiz-Altisent (1996) developed a "lateral impact sensor" consisting of a small arm with lateral movement that impacts the fruit with a semi-spherical head. A piezoelectric accelerometer located on this head estimates fruit firmness. Lateral impact sensor was adapted for use with a conveyor belt (Chen and Ruiz-Altisent, 1996; García-Ramos et al., 2003). Peach and apple firmness could be measured at a maximum speed of 6 fruits per second. A step forward in this technique was the development of a manual impact sensor shaped like a gun. This sensor can be used in orchards to determine the optimum harvest date (Chen et al., 2000). Delwiche et al. (1996) developed a sensor, based on the impact technique, that acts horizontally and consists of a cylindrical head with an attached accelerometer, all moved by a pneumatic cylinder. The sensor was installed successfully in an experimental packing line (Delwiche et al., 1996).

Impact techniques can also involve dropping the test fruit onto a load cell. Moltó et al. (1996) and Gutiérrez et al. (1999) described a sensor based on this idea, the load cell recording the impact when the fruit falls on it. The sensor, patented in Spain by IVIA (the Valencian Institute for Agricultural Research) and FOMESA (Food Machinery Española, S.A.), has been used to detect puffed clementines online at a speed of 5 fruits per second and with an accuracy of over $90 \%$ (Moltó et al., 1996).

All the equipments described above have been developed by research groups and is currently being used in the form of prototypes. However, some companies are marketing various forms of impact apparatus for online use (the sensors used are usually piezoelectric, providing a voltage signal proportional to the impact force in a manner similar to an accelerometer). For example: the impact/acoustic firmness sensor (AFS) by Aweta, Greefa (iFD, intelligent firmness detector), Sinclair iQ firmness tester. These sensors have been tested with apples, avocados, citrus fruits, kiwis, plums, nectarines, peaches and many other fruits (Howarth and Ioannides, 2002). These sensors are capable of measuring 6-10 fruits per second. Bench-top versions of these equipments are commercially available, and handheld versions are being developed for field or on-tree measurements (Slaughter et al., 2009).

\section{Acoustic response for firmness and structural defects}

Non-destructive techniques of using acoustic and vibrational characteristics for determining internal properties of fruits and vegetables, mainly flesh texture, have been the subject of numerous investigations over the past several decades. In order to obtain an objective and non-destructive measurement of firmness, several techniques (Chen and Sun, 1991; Abbott, 1999) and theoretical models (Huarng et al., 1993) about the dynamic behavior of these biological materials were developed many years ago. These models mainly assume that the object is spherical and approximately elastic. Cooke and Rand (1973) proposed a mathematical model for the modulus of elasticity:

$E=C \cdot f^{2} \cdot m^{2 / 3} \cdot \rho^{1 / 3}$,

where $E$ is the coefficient of elasticity (Pa), $C$ is a constant, $f$ is the frequency for the highest amplitude $(\mathrm{Hz}), m$ is the mass and $\rho$ is the density $\left(\mathrm{kg} \mathrm{m}^{-3}\right)$. Since the 1990 s several research groups (Chen et al., 1996; Abbott et al., 1997) and others have done extensive research on simulating sonic vibrational behavior for different shapes of fruits.

In these techniques, the product is excited by means of a small impact, and the vibration (about $20-20,000 \mathrm{~Hz}$ ) is measured using a microphone, piezoelectric sensors or laser vibrometers. The acoustic signal captured is Fourier transformed and the main frequencies calculated. Resonant frequencies observed in the fruit relate to elasticity, density, size and shape of the object. Resonant frequencies of some fruits and vegetables (apples, melons, peaches, tomatoes, etc.) have been associated with firmness using coefficients described as "stiffness coefficient" or "firmness coefficient". The stiffness coefficient was formerly defined as $f^{2} m$, where $f$ is a selected resonant frequency, and $m$ is the mass of the fruit. This was later corrected and replaced by the expression $f^{2} m^{2 / 3}$, but in recent works $f^{2} m$ has been applied (Fekete and Felföldi, 2000). Depending on the published applications, $f$ can be the first, second, third, or the highest resonant frequency, or any other combination. In the determination of peach firmness, the second resonant frequency is used (Clark and Shackelford, 1973); for testing the texture of apples, the second or third resonant frequencies can be used (Abbott and Liljedahl, 1994), for pineapples the first resonant frequency is used by some authors (Chen and De Baerdemaeker, 1993) and the third one is proposed (Pathaveerat et al., 2008), while for pear the second frequency is considered (Taniwaki et al., 2009b). A handheld prototype was developed to measure firmness while the fruits were still on the tree using the stiffness factor $f^{2} m^{2 / 3}$ (Zude et al., 2006).

These coefficients and their theoretical basis are appropriate for regular shapes (sphere, axisymmetric spheroid), but they are also applied to more irregular fruit shapes. If the fruit or vegetable shape is far from spherical, adapted firmness indices including a measure of shape is proposed by some authors (Jancsók et al., 2001).

Correlations between the textural characteristics of fruits and vegetables and other vibration or sonic variables, e.g., pulse propagation velocity, damping coefficient and band magnitude, have also been studied earlier (Garret and Furry, 1972; Sugiyama et al., 1998) and recently (Taniwaki et al., 2009a).

Non-destructive techniques using sonic characteristics of fruits and vegetable have been applied also for detecting internal disorders and classification: internal creases or voids in seedless watermelons by impacting the fruit (Diezma-Iglesias et al., 2004) dropping potato tuber onto an instrumented surface (Elbatawi, 2008), or sorting pistachio nuts with closed shells from those with open shells (Pearson, 2001).

Several commercial sonic devices have been also developed: the AFS by Aweta, mentioned before, is a good example that combines acoustic and impact responses: the excitation impact is generated mechanically on the bottom of the fruit and a microphone records the vibration. Both responses, impact and acoustic, are used in dedicated algorithms which are able to measure firmness of apples in a large range accurately (Herrero-Langreo, 2010). The combination of two and more types of different sensors, mainly for fruit ripeness assessment has been stressed for long time. RuizAltisent et al. (2006) showed that in peaches, up to $91 \%$ of the total variability in ripeness was obtained by combining optical (VIS) and mechanical measurements (optical reflectance). This opens a new way for increasing the accuracy and robustness of sensors in practice.

\section{Chemical sensors}

There is a need for quick testing for both individual chemical compounds and composite mixtures of different nature (Snopok and Kruglenko, 2002); also a non-destructive, noninvasive approach is desirable, able to correlate information available on the product with the stage of freshness and quality. Low-cost and continuous monitoring of chemical and microbiological quality (including microbiological examination of food: aerobic colony count, presence and/or number of pathogens), with fast response times, can be achieved with chemical sensors. 


\subsection{High selectivity versus low selectivity sensors}

According to the International Union of Pure and Applied Chemistry (IUPAC) nomenclature, "a chemical sensor is a device that transforms chemical information, ranging from the concentration of a specific sample component to total composition analysis, into an analytical useful signal. Chemical sensors usually contain two basic components connected in series: a chemical (molecular) recognition system (receptor) and a physico-chemical transducer" (Snopok and Kruglenko, 2002).

Chemical sensors may be classified according to the chemical specificity-conferring mechanism; biosensors are a subgroup of chemical sensors which incorporate a biological or biomimetic sensing element. The main biological materials used in biosensor technology are the couples enzyme/substrate, antibody/antigen and nucleic acids/complementary sequences. The selectivity of the biological sensing element offers the opportunity for development of highly specific devices for real-time analysis in complex mixtures (Velasco-Garcia and Mottram, 2003). The most important area of interest for the biosensor application is the detection of pathogens, pesticides, microorganisms and toxins (Mello and Kubota, 2002).

Typically, a "lock-and-key" approach is not suitable for simulation of human preferences to the composition of complex mixtures as foods or beverages. Snopok and Kruglenko (2002) described a multi-component chemical media (MCM) not by a sum of their individual components (or corresponding responses from the specific sensors) but by some abstract representation, a chemical image $(\mathrm{CI})$ as a fingerprint where a set of parameters characterize a given MCM. An "electronic nose", which mimics the human olfaction, is an example of "electronic sensing" based on arrays of low-selective/cross-reactive sensors, which combined responses and coupled with an appropriate pattern recognition system, allow characterizing a gaseous sample as a global fingerprint or chemical image.

\section{Biosensors}

The biological recognition element of a biosensor can be classified into two main classes: biocatalysts (enzymes, microorganisms, tissue materials) and bioligands (antibodies, nucleic acids, lectins). The traditional transducers are electrochemical, optical and thermal. The latest generation of biosensors (affinity biosensors) combine the classical measurement principles with piezoelectric and magnetic transducers (Castillo et al., 2004).

More than 10 years ago Lowe (1999) already expressed that "there is a general consensus that a number of new opportunities for biosensors are appearing in agri-food production and process monitoring". In the specific case of postharvest management of specialty crops, the most important concerns are the following issues (summarized in Table 4).
(1) Detection of pesticide residues. Enzyme bioreceptors are widely employed for this application. Amine et al. (2006) estimate that about $71 \%$ of the applications described for these enzymatic biosensors are for the determination of pesticides including carbamates and organophosphorus compounds, while heavy metals detection represent only $21 \%$. These biosensors are based mainly on the inhibition of Acetylcholinesterase (AchE), but using different signal transduction methods. Velasco-Garcia and Mottram (2003) presented in their review some practical applications: pH-sensitive transducers were successfully applied to the quantification of the pesticide propoxur in onion and lettuce samples, for the determination of heavy metal ions and phosphororganic pesticides in contaminated potatoes and a biosensor based on AchE immobilized onto magnetic particles in a photometric flow injection system could detect methamidophos (organophosphate insecticide) in lettuce and cabbage. More recently Nagatani et al. (2007) have developed pesticide residue detection visual chips based on AchE, which could differentiate between concentrations of 0.1 and $0.2 \mathrm{ppm}$ of diazinon-oxon in real samples of apple and orange juice.

(2) Quality control in storage atmospheres. Determination of ethanol is important in agricultural and environmental analysis as for example in modified-atmosphere packages and controlledatmosphere storage as a technique for low oxygen injury detection during the handling of fruits and vegetable (VelascoGarcia and Mottram, 2003). The most promising ethanol sensors developed up to date are the bienzymatic sensors based on the co-immobilization of the enzymes alcohol oxidase with horseradish peroxidase, bienzymatic system that has been used to develop commercial colorimetric sensors which are able to detect low- $\mathrm{O}_{2}$ injury in modified-atmosphere packages containing fresh cut fruits and vegetables (Azevedo et al., 2005).

(3) Foodborne pathogen and toxins detection in fruits and vegetables. According to Lazcka et al. (2007) biosensors are at the present the fastest growing technology for pathogen detection, being possible in a near future that this analytical technique can replace the reference test ELISA. This is a great interest area not only due to their potential toxicity detection, but also due to being indicators for freshness or spoilage of fruits and vegetable (Saaid et al., 2009; Velusamy et al., 2010). Nayak et al. (2009) in their review, present an application of light scattering biosensors for the detection of target bacteria viz. L. monocytogenes, E. coli 0157:H7 and Salmonella in vegetable and meat samples spiked with these bacteria. The forward scattering was able to detect the presence of contaminants accurately based on the distinct colony/scatter signature. The detection limit of this system was single cell per $25 \mathrm{~g}$ portion of test specimen. On the other hand moulds of the genera Aspergillus and Penicillium occur in different fruits, producing several mycotoxins than have been described as toxinogenic. Leung et al. (2007) in their review about fiber-optic biosensor described a fluo-

Table 4

Main objectives and technologies involved in biosensing.

\begin{tabular}{|c|c|c|}
\hline Objectives & Technologies & References \\
\hline Detection of pesticide residues & $\begin{array}{l}\text { Enzyme bioreceptors } \\
\text { pH-sensitive transducers } \\
\text { Pesticide residue detection visual chips based on AchE }\end{array}$ & $\begin{array}{l}\text { Amine et al. (2006) } \\
\text { Velasco-Garcia and Mottram (2003) } \\
2007\end{array}$ \\
\hline Quality control in storage atmospheres & $\begin{array}{l}\text { Co-immobilization of the enzymes alcohol oxidase with } \\
\text { horseradish peroxidase }\end{array}$ & Azevedo et al. (2005) \\
\hline \multirow{4}{*}{$\begin{array}{l}\text { Foodborne pathogen and toxins } \\
\text { detection in fruits and vegetables }\end{array}$} & Optical-based biosensors & Velusamy et al. (2010) \\
\hline & $\begin{array}{l}\text { Light scattering biosensors for the detection of target bacteria } \\
\text { viz. L. monocytogenes, E. coli 0157:H7 and Salmonella }\end{array}$ & Nayak et al. (2009) \\
\hline & Fluorescent sensor to detect fumonisins and aflatoxins & Leung et al. (2007) \\
\hline & $\begin{array}{l}\text { Antennae of Colorado potato beetle for detecting Phytophtora } \\
\text { infestans }\end{array}$ & Velasco-Garcia and Mottram (2003) \\
\hline
\end{tabular}


rescent sensor to detect fumonisins and aflatoxins in maize, using a competitive assay, on the one hand, to measure fumonisin B-1 (FB1); the antibody to FB1 was covalently bonded to the fiber, the fluorescence signal was inversely proportional to the concentration of FB1. On the other hand the mycotoxin aflatoxin $\mathrm{B}-1(\mathrm{AFB}(1))$ was detected using a non-competitive assay because the $\operatorname{AFB}(1)$ fluoresces. The fluorescent signal in this case was directly proportional to the concentration of $\mathrm{AFB}(1)$. The detection limit was $2 \mathrm{ng} / \mathrm{mL}$ of AFB(1). A biosensor based on the intact antennae of Colorado potato beetle (Leptinotarsa decemlineata) was developed to detect marker volatiles released by potato tubers infested with Phytophtora infestans fungus (aflatoxins producer). The biosensor was able to detect one single diseased potato tuber within up to $100 \mathrm{~kg}$ potato tubers (Velasco-Garcia and Mottram, 2003).

In spite of the applications described in previous paragraphs, there are relatively few publications on biosensors applied in postharvest technology. The extended review by Rich and Myszka (2007) on commercial optical biosensors, shows 14 papers under "Food, agricultural, veterinary and environmental sciences". Among them there are no applications reported on fruit and vegetable postharvest control quality.

An important remark is that the majority of the biosensors cited are to be used in a liquid phase (sometimes used to build the equipment called "electronic tongues"), showing that the non-destructive approach is still far in the case of solid samples. In general among other drawbacks that biosensors have to overcome are the limited lifetime of the biological components, the lack of selectivity in real complex matrices, the improvement of the sensor devices (in sensitivity and in reproducibility) and the cost for mass commercial production.

\subsection{Electronic nose}

The concept of the electronic nose (EN) was already formulated by Gardner and Bartlett in 1993 as an instrument capable of recognizing simple or complex odors. It is possible to build a fingerprint that represents the global effect of the aroma food sample, with the sensor array response for the interaction of the aroma components with the receptor sites in function of the chemical specificityconferring mechanism and the mode of physico-chemical signal transduction (semiconductor, transistor and piezoelectric transducers are the most used) (Snopok and Kruglenko, 2002).

From the postharvest management point of view, in fruit ripeness the most important changes in fruit aroma are experienced during the shelf-life period (Brezmes et al., 2001b), but a number of other factors influence volatile emission after fruit storage, mainly storage treatment including period as well as $\mathrm{O}_{2}$ and $\mathrm{CO}_{2}$ concentrations in the storage atmosphere. Fruit aroma, or any other volatiles related to the process, are potential indicators of the physiological condition of the fruit, which can be used to develop consistent and reproducible non-destructive techniques to evaluate fruit quality from harvest to consumer (Pathange et al., 2006).

The technique of global aroma analysis by means of EN has been considered very promising during the last 15 years as a non-destructive tool to evaluate fruit quality, as shown in the comprehensive review of Peris and Escuder-Gilabert (2009), from different points of view: shelf-life investigation to assess "Jonagold" (Saevels et al., 2003) and "Pinklady" (Brezmes et al., 2001a) apples quality during shelf-life, to monitor tomato fruit with different storage time (Gómez et al., 2008); harvest date determinations in mandarins (Gomez et al., 2006), apples (Saevels et al., 2003) and mango fruit (Lebrun et al., 2008), to classify "Gala” apples at harvest in different maturity degrees (Pathange et al., 2006), faults detection as to detect freeze damage in oranges (Tan et al., 2005) or apples defects as mealiness and skin damage in "Cox" (di Natale et al., 2001) and "Red Delicious" apples (Li et al., 2007), and for blueberry fruit disease detection and classification (Li et al., 2010).

Nevertheless at the current stage the expectations have not been achieved in a majority of applications. Both the headspace generation from the sample and the response of sensors, depend on numerous factors that are very difficult to control. The efficiency at generating the headspace is generally low due to external parameters such as temperature or relative humidity and the gas/volatile composition of the environment. In addition important internal parameters, as the nature of the substrate, affect the headspace generation. Concerning the sensors characteristics, common restrictions can be summarized as: lack of sensitivity, lack of linearity, lack of specificity and short- and long-term time drifts. Thus, further research is being carried out to overcome these constraints: basic knowledge of gas/volatiles mixtures and interactions and improvements in the gas transfer components.

In spite of the optimism for the potential of biosensors with a great number of publications on biosensors applied in food analysis, their emergence from the research laboratory to the market has been slow and only a few systems are commercially available.

On the other hand commercial ENs are available in several shapes such as portable (handheld) devices (e.g., 4200 Portable zNose of Electronic Sensor Technology, LP), but mainly as laboratory instruments (e.g., FOX series of ALPHA M.O.S. or LibraNOSE of Technobiochip) using matrix arrays ranging from 8 to 32 sensors. However, the above-mentioned restrictions (headspace generation and sensors response) are obviously the cause of difficulties arising when trying to achieve robust sensor correlations with reference techniques (Mielle and Marquis, 2001). As a consequence, it is not possible to use systematically the EN, not even in industry quality laboratories, without previously carrying out an exhaustive study to identify, control and eliminate those sources of variation that affect the EN measurements for every specific application. Che Harun et al. (2009) proposed a new architecture for a new generation of electronic noses named e-Mucosa. The system combines two odor separation columns with three miniaturized sensor arrays of 200 chemoresistive sensors each, in a portable device with integrated electronics and microfluidic components. A new dimension appears in the data matrix, working with the pattern recognition system in this case with spatio-temporal signals.

The construction of integrated systems that use an array of chemical sensors for electronic nose devices or auto-analyzers of high specificity needs: (1) to design new sensor technologies (sensitive layers, transducers) or to improve the existing ones, and to improve the automated manufacturing technologies to eliminate batch-to-batch variability so as to make them appropriate for commercial mass production, and (2) the integration of the sensor array with an appropriate sample extraction system, fluidics, sensor/sample interface and dedicated electronics. These systems should be coupled to Multisensor Data Fusion (MDF) technology (including signal processing, pattern recognition, statistical estimation, artificial intelligence, and control theory) to fuse data from multiple sensors in order to improve the accuracy of the estimation of the environment (Huang et al., 2007). Finally, there are at least two other developments that are expected to have significant impact in the area of (bio)sensors: the laboratory in a chip, and nanotechnology: metal-oxide semiconducting nanowires or nanotubes can be used for the construction of, for example, gas sensors and electrochemical biosensors. These quasi-one-dimensional nanostructures are essential for the advancement of chemical sensors and will have important impact on the exploration of nanoscale devices, sensors, and detectors using electric, optical, electrochemical and magnetic transducers (Liu, 2008; Xia et al., 2010), for the fabrication of credit-card sized microlaboratories and even for in vivo detection. 
Table 5

Summary of recent wireless sensing technology (WST) applications in specialty crops.

\begin{tabular}{ll}
\hline Category & Subject \\
\hline WSN & Sensor network configurations and applic ations for vineyards \\
WSN & addressing heat summation and potential frost damage in wine production \\
WSN & ZigBee based remote sensing network \\
WSN & Pest control. Fighting phytophtora in a potato field \\
WSN & Distributed greenhouse control \\
WSN & Monitor and control the environment in greenhouses with melon and cabbage \\
WSN & Measuring substrate water, temperature, electrical conductivity, daily \\
& photosynthetic radiation and leaf wetness in real-time \\
WSN & Monitoring system based on ZigBee for greenhouses \\
WSN & Measuring differences in spatial temperature and humidity in Greenhouse \\
& Horticulture \\
RFID & Imaging and environmental sensing in greenhouses \\
Wireless sensor node & Monitoring greenhouses \\
Wireless sensor node & Measuring soil parameters in precision horticulture (temperature, humidity, \\
& salinity and electrical conductivity) \\
WSN & Monitoring refrigerated chamber in wholesale storage \\
\hline
\end{tabular}

\section{Wireless sensing in specialty crops}

The use of wireless sensor technologies (WST) in specialty crops offers new features both in terms of sensing and communications that never have been available before. Recent advances in wireless sensor networking (WSN) technology have led to the development of low-cost, low power, multifunctional sensor nodes. Sensor nodes enable environment sensing together with data processing. They are able to network with other sensors systems and exchange data with external users. The application of this technology for monitoring crops that are intensively cultivated is new, since the necessary hardware has only recently become available. However, some applications have been demonstrated for specialty crops (see Table 5).

WSN is one of the most significant technologies in the 21 st century. RFID was developed for identification purposes, but growing interest in the many other possible applications has led to the development of a new range of wireless sensor devices based on RFID. The main difference between a WSN and a RFID system is that RFID devices have no cooperative capabilities, while WSN allow different network topologies and multihop communication. A multihop network is dynamically self-organized, with the nodes establishing and maintaining mesh connectivity among themselves. Motes (small single nodes) can form networks and cooperate according to various models and architectures. They come with miniaturized mounted sensors that allow, in a small space $(2.5 \mathrm{~cm} \times 5 \mathrm{~cm} \times 5 \mathrm{~cm})$, the gathering of data not only just about temperature, but also relative humidity, acceleration, shock and light (Ruiz-Garcia et al., 2009). In the case of RFID, there are commercial active and semipassive tags that can collect temperature information (Amador et al., 2009; Jedermann et al., 2009). Other semi-passive tags outfitted with sensors are under development, like for humidity (Chang et al., 2007; Abad et al., 2009), shock/vibration (Todd et al., 2009), light (Cho et al., 2005; Abad et al., 2009), pH (Steinberg and Steinberg, 2009) and concentration of gases such as acetaldehyde or ethylene (Vergara et al., 2006). Biosensor tags are also being investigated. These tags could be used for detecting bacterial contamination in food products along the supply chain (Wentworth, 2003).

Another advantage for wireless sensor devices is the feasibility of installation in places where cabling is impossible, such as large fields (Morais et al., 2008) or embedded within the implements, which brings their readings closer to the true in situ properties of crops (Ruiz-Garcia et al., 2009).

Most of the applications of wireless sensors in specialty crops have been in monitoring environmental and growing conditions, in field and in the greenhouse. Only with a WSN is it possible to monitor a whole orchard deploying 20 or 30 sensors per hectare, or track the temperature in each flower pot in a greenhouse; these may be distributed in plots averaging for example 4 ha in size and situated up to $10 \mathrm{~km}$ apart (Lopez et al., 2009). In these situations, monitoring is impossible with standard cabling technologies. Different configurations have been investigated for monitoring vineyards: (Burrell et al., 2004) described a variety of sensor network configurations and applications that can address different priorities in the vineyard; in field experiments up to 198 sensors and 50 nodes were deployed in about 9 ha of vineyards to send data to a remote server (Bencini et al., 2009).

Beckwith et al. (2004) implemented a WSN consisting of 65 motes of $916 \mathrm{MHz}$, with the aim of addressing two important parameters in wine production: heat summation and potential frost damage. Morais et al. (2008) showed the feasibility of a ZigBee based remote sensing network, where batteries were recharged with energy harvested from up to three sources (photonic energy, kinetic energy from moving water in irrigation pipes and from wind).

Pest and disease control is an important field for the application of WST in specialty crops: Baggio (2005) deployed a WSN for fighting phytophtora infection in a potato field, which depends on the climatological conditions. 868 and $916 \mathrm{MHz}$ motes were used for measuring humidity and temperature coupled with predicting models (Baggio, 2005).

Greenhouse production can greatly benefit from WST. The first application of WSN in a greenhouse was reported in the year 2003; it was a monitoring and control system developed by means of Bluetooth (Liu and Ying, 2003). Since that year, several applications have been developed, most of them making use of IEEE 802.15.4/ZigBee protocol (IEEE, 2003; Gonda and Cugnasca, 2006; Lea-Cox et al., 2007; Liu et al., 2007; Yoo et al., 2007; van Tuijl et al., 2008), including multi-spectral imaging for remote sensing of the canopy of seedlings (Wang et al., 2008; Yang et al., 2008).

The most advanced systems integrate a variety of sensors, which can measure substrate water, soil and air temperatures, soil electrical conductivity, daily photosynthetic radiation and leaf wetness in real-time. Resulting benefits that have been demonstrated include control for improved plant growth, more efficient water and fertilizer applications, together with a reduction in disease problems related to over-watering, and therefore for optimizing quality of the crops.

Further important applications showing high potential are monitoring fruit and vegetable containers and cold-storage facilities, with or without controlled atmosphere (Ruiz-Garcia et al., 2008) or monitoring quality and senescence of specialty crops during transport (Ruiz-Garcia, 2008). Many other potential applications in the field and greenhouse, and in relation to quality and safety of prod- 
ucts and to precision farming, can be envisaged. Wireless sensor technologies hold an important niche in fruit and vegetable quality research laboratories.

\section{Summary and conclusions}

This review has attempted to provide an overview of existing and promising sensing technologies with an emphasis on their current and future application potential for the specialty crop industry. Several technologies were reviewed, mainly: (1) electromagnetic sensors, spectroscopic and computer vision; (2) mechanical contact and acoustic sensors; (3) biosensors; and (4) wireless sensors networks.

Advances in laboratory instrumentation have made it possible to introduce a variety of sensors for practical applications in specialty crops, but the transfer of the promising, and in many cases proven techniques to the industry is taking place at slow pace. Computer vision-based online fruit grading systems are already in use in Europe and the USA (Kondo, 2010); however, they are only used fort basic color and size measurements. Hence, there are great opportunities for turning these promising or proven techniques into computerized and automated equipment for commercial applications, given that:

- Computer vision linked to robotics has already been demonstrated as a basic component of automated operations in many industries.

- Machine vision is fast, cost-effective and easy to automate, and can operate under rugged, hostile environments.

- Problems such as dust, water spills, product residues or potential light source variations have already be solved in commercial application of NIR-based technology.

- Automation and robotics are already present in some operations for many industries. Unlike conventional machines, automated systems are able to handle a great amount of information. However, understanding of the diversity and complexity of biomaterial properties is needed in development of sensors and their systems.

As computer capabilities and processing speed are continually improving, the emergence of new spectral regions (MIR, X-rays), NMR and photoluminescence, and multi- and hyperspectral imaging is likely to present great opportunities in quality and safety inspection of specialty crops. However, these emerging technologies will need further research efforts in order to meet the online inspection requirements, and such efforts have already begun.

Moreover, there is a need for portable equipment for use in the field and packinghouse as a support for mechanised and automated processes. Portable, on-site sensing networks that integrate information collection, processing and analysis, and management are needed for on-tree monitoring of the quality and condition of specialty crops.

For improving management decisions, sensor networks based on wireless communication show a high capability of increasing sensing capacity for specialty crop production and quality monitoring. Ornamentals production systems have a different infrastructural and commercial environment, and the application of the sensing principles is scarce. However, the techniques presented in this paper, especially computer vision, are shown to be very appropriate for this sector.

Logistics management and traceability need the development of sensors networks which are reliable, easy to implement and of low-cost. RFID readers with onboard environmental and volatiles sensing capabilities, together with flexible tags, show great promise for monitoring product quality and safety in large containers and long-distance transportation.
In conclusion, many sensing technologies have been developed in the past, and further research and development are needed to meet the needs of specialty crop industries. Greater contribution and involvement from the equipment manufacturing industry is essential for moving the developed technologies from research laboratories to specialty crop processing and packing houses. The success of any online technology for sorting and grading fruit and vegetables will be dependent upon its added commercial value for the specialty crop industry. Only when consumers are willing to pay premium prices for, e.g., extra sweet fruit, will auctions and packinghouses adopt such new grading lines and change their quality grading standards that are now almost exclusively based on external appearance.

\section{References}

Abad, E., Palacio, F., Nuin, M., González de Zárate, A., Juarros, A., Gómez, J.M., Marco, S., 2009. RFID smart tag for traceability and cold chain monitoring of foods: demonstration in an intercontinental fresh fish logistic chain. Journal of Food Engineering 93 (4).

Abbott, J.A., 1999. Quality measurement of fruits and vegetables. Postharvest Biology and Technology 15 (3), 207-225.

Abbott, J.A., 2004. Textural quality assessment for fresh fruits and vegetables. Quality of Fresh and Processed Foods 542, 265-279.

Abbott, J.A., Liljedahl, L.A., 1994. Relationship of sonic resonant frequency to compression test and Magness-Taylor firmness of apples during refrigerated storage. Transactions of the ASAE 37 (4), 1211-1215.

Abbott, J.A., Lu, R., Upchurch, B.L., Stroshine, R.L., 1997. Technologies for nondestructive quality evaluation of fruits and vegetables. Horticultural Reviews 1997 (20) $1-10$.

Abdullah, M.Z., Mohamad-Saleh, J., Fathinul-Syahir, A.S., Mohd-Azemi, B.M.N., 2006. Discrimination and classification of fresh-cut starfruits (Averrhoa carambola L.) using automated machine vision system. Journal of Food Engineering 76 (4) 506-523.

Aguilera, J.M., Briones, V., 2005. Computer vision and food quality. Food Australia 57 (3), 79-87.

Aleixos, N., 1999. Desarrollo de técnicas de visión artificial, utilizando procesadores digitales de señal. Aplicación a la detección de defectos en frutas en tiempo real. Ph.D. Dissertation. Universidad Politécnica de Valencia (Spain).

Aleixos, N., Blasco, J., Navarron, F., Molto, E., 2002. Multispectral inspection of citrus in real-time using machine vision and digital signal processors. Computers and Electronics in Agriculture 33 (2), 121-137.

Amador, C., Emond, J.P., Nunes, M.C.N., 2009. Application of RFID technologies in the temperature mapping of the pineapple supply chain. Sensing and Instrumentation for Food Quality and Safety 2009 (3), 26-33.

Amine, A., Mohammadi, H., Bourais, I., Palleschi, G., 2006. Enzyme inhibition-based biosensors for food safety and environmental monitoring. Biosensors and Bioelectronics 21 (8), 1405-1423.

Ariana, D.P., Lu, R.F., 2010. Evaluation of internal defect and surface color of whole pickles using hyperspectral imaging. Journal of Food Engineering 96 (4), 583-590.

Aristizábal, I.D., 2007. La resonancia magnética y sus aplicaciones en la agroindustria, una revisión. Rev. Fac. Nal. Agr. Medellín 60 (2), 4037-4066.

Aristizabal Torres, I.D., 2006. Estudio, aplicación y propuesta de automatización del procesamiento de imágenes por resonancia magnética para la evaluación y detección de defectos internos de calidad en cítricos y melocotones. Departamento de Mecanización y Tecnología Agraria, Universidad Politécnica de Valencia, Valencia.

Azevedo, A.M., Prazeres, D.M.F., Cabral, J.M.S., Fonseca, L.P., 2005. Ethanol biosensors based on alcohol oxidase. Biosensors and Bioelectronics 21 (2), 235247.

Baggio, A., 2005. Wireless sensor networks in precision agriculture. In: Workshop on Real-World Wireless Sensor Networks. REALWSN'05, Sweden.

Barcelon, E.G., Tojo, S., Watanabe, K., 1999a. Relating X-ray absorption and some quality characteristics of mango fruit (Mangifera indica L.). Journal of Agricultural and Food Chemistry 47 (9), 3822-3825.

Barcelon, E.G., Tojo, S., Watanabe, K., 1999b. X-ray CT imaging and quality detection of peach at different physiological maturity. Transactions of the ASAE 42 (2), 435-441.

Barreiro, P., Zheng, C., Sun, D.W., Hernandez-Sanchez, N., Perez-Sanchez, J.M., RuizCabelloc, J., 2008. Non-destructive seed detection in mandarins: comparison of automatic threshold methods in FLASH and COMSPIRA MRIs. Postharvest Biology and Technology 47 (2), 189-198.

Barry, C.S., 2009. The stay-green revolution: recent progress in deciphering the mechanisms of chlorophyll degradation in higher plants. Plant Science 176 (3), 325-333.

Bato, P.M., Nagata, M., Cao, Q., Hiyoshi, K., Kitahara, T., 2000. Study on Sorting SyStem for Strawberry Using Machine Vision. Part 2. Development of Sorting System with Direction and Judgement Functions for Strawberry (Akihime variety). Journal of the Japanese Society of Agricultural Machinery 62 (2), 101110. 
Beckwith, R., Teibel, D., Bowen, P., 2004. Report from the field: results from an agricultural wireless sensor network. In: Paper Read at 29th Annual IEEE International Conference on Local Computer Networks, 16-18 November, p. 2004.

Belasque, J., Gasparoto, M.C.G., Marcassa, L.G., 2008. Detection of mechanical and disease stresses in citrus plants by fluorescence spectroscopy. Applied Optics 47 (11), 1922-1926.

Bellon-Maurel, V., 1992. Application de la spectroscopie proche infrarouge au contrôle en ligne de la qualité des fruits et legumes. l'Institut National Polytechnique de Toulouse, France.

Bencini, L., Collodi, G., Di Palma, D., Manes, A., Manes, G., 2009. Advanced distributed monitoring system for agriculture based on wireless sensor network technology. In: Xin, F.S.Z.A.J. (Ed.), Proceedings of the 7th World Congress on Computers in Agriculture and Natural Resources. ASABE, Reno, NV, USA

Beullens, K., Kirsanov, D., Irudayaraj, J., Rudnitskaya, A., Legin, A., Nicolaï, B.M., Lammertyn, J., 2006. The electronic tongue and ATR-FTIR for rapid detection of sugars and acids in tomatoes. Sensors and Actuators B: Chemical 116 (1-2), 107115 .

Birth, G.S., Dull, G.G., Renfroe, W.T., Kays, S.J., 1985. Nondestructive spectrophotometric determination of dry-matter in onions. Journal of the American Society for Horticultural Science 110 (2), 297-303.

Blasco, J., Aleixos, N., Molto, E., 2007. Computer vision detection of peel defects in citrus by means of a region oriented segmentation algorithm. Journal of Food Engineering 81 (3), 535-543.

Brecht, J.K., Shewfelt, R.L., Garner, J.C., Tollner, E.W., 1991. Using X-ray-computed tomography to nondestructively determine maturity of green tomatoes. Hortscience 26 (1), 45-47.

Brezmes, J., Llobet, E., Vilanova, X., Orts, J., Saiz, G., Correig, X., 2001a. Correlation between electronic nose signals and fruit quality indicators on shelf-life measurements with pinklady apples. Sensors and Actuators B: Chemical 80 (1), $41-50$.

Brezmes, J., Llobet, E., Vilanova, X., Saiz, G., Correig, X., 2001b. Evaluation of the electronic nose as a novel instrument to assess fruit ripeness. In: Paper Read at EURODEUR-AIRODEUR. La Metrologie des Odeurs el les Nez Electroniques, Paris.

Brosnan, T., Sun, D.-W., 2002. Inspection and grading of agricultural and food products by computer vision systems-a review. Computers and Electronics in Agriculture $36(2-3), 193-213$.

Brosnan, T., Sun, D.W., 2004. Improving quality inspection of food products by computer vision-a review. Journal of Food Engineering 61 (1), 3-16.

Burrell, J., Brooke, T., Beckwith, R., 2004. Vineyard computing: sensors networks in agricultural production. Pervasive Computing 3 (1), 38-45.

Butz, P., Hofmann, C., Tauscher, B., 2005. Recent developments in noninvasive techniques for fresh fruit and vegetable internal quality analysis. Journal of Food Science 70, 131-141.

Castillo, J., Gßspßr, S., Leth, S., Niculescu, M., Mortari, A., Bontidean, I., Soukharev, V., Dorneanu, S.A., Ryabov, A.D., Cs $\div$ regi, E., 2004. Biosensors for life quality: design, development and applications. Sensors and Actuators B: Chemical 102 (2), 179-194.

Clark, C.J., MacFall, J.S., 2003. Quantitative magnetic resonance imaging of 'Fuyu' persimmon fruit during development and ripening. Magnetic Resonance Imaging 21 (6), 679-685.

Clark, C.J., McGlone, V.A., Jordan, R.B., 2003. Detection of Brownheart in [']Braeburn' apple by transmission NIR spectroscopy. Postharvest Biology and Technology 28 (1), 87-96.

Clark, J.R., Shackelford, P.S., 1973. Resonance and optical properties of peaches as related to flesh firmness. Transactions of the ASAE 47 (4), 1313-1320.

Clayton, M., Biasi, B., Mitcham, B., 1998. New devices for measuring firmness of cherries. Perishables Handling Quarterly 92, 2-4.

Cooke, J.R., Rand, R.H., 1973. A mathematical study of resonance in intact fruits and vegetables using a 3-media elastic sphere model. Journal of Agricultural Engineering Research 18 (2), 141-157.

Crisosto, C.H., Valero, C., Slaughter, D.C., 2007. Predicting pitting damage during processing in Californian clingstone peaches using color and firmness measurements. Applied Engineering in Agriculture 23 (2), 189-194.

Cubeddu, R., D'Andrea, C., Pifferi, A., Taroni, P., Torricelli, A., Valentini, G., Dover, C., Johnson, D., Ruiz-Altisent, M., Valero, C., 2001. Nondestructive quantification of chemical and physical properties of fruits by time-resolved reflectance spectroscopy in the wavelength range 650-1000 nm. Applied Optics 40 (4), 538-543.

Chang, K., Kim, Y.H., Kim, Y., Yoon, Y.J., 2007. Functional antenna integrated with relative humidity sensor using synthesised polyimide for passive RFID sensing. Electronics Letters 43 (5), 259-260.

Chao, K., Yang, C.C., Kim, M.S., Chan, D.E., 2008. High throughput spectral imaging system for wholesomeness inspection of chicken. Applied Engineering in Agriculture 24 (4), 475-485

Chayaprasert, W., Stroshine, R., 2005. Rapid sensing of internal browning in whole apples using a low-cost, low-field proton magnetic resonance sensor. Postharvest Biology and Technology 36 (3), 291-301.

Che Harun, F.K., Covington, J.A., Gardner, J.W., 2009. Portable e-mucosa system: mimicking the biological olfactory. Procedia Chemistry 1 (1), 991-994.

Chen, H., De Baerdemaeker, J., 1993. Modal analysis of the dynamic behaviour of pineapples and its relation to fruit firmness. Transactions of the ASAE 36 (5), 1439-1444.

Chen, P., Ruiz-Altisent, M., 1996. A low-mass impact sensor for high-speed firmness sensing of fruits. In: Paper Read at Proceedings International Conference of Agricultural Engineering, Madrid, Spain.

Chen, P., RuizAltisent, M., Barreiro, P., 1996. Effect of impacting mass on firmness sensing of fruits. Transactions of the ASAE 39 (3), 1019-1023.
Chen, P., Sarig, Y., Thompson, J.F., 2000. A hand-held impact sensor for firmness sensing of fruits. In: Paper Read at Proceedings Postharvest Congress, 2000, Jerusalem, Israel.

Chen, P., Sun, Z., 1991. A review of non-destructive methods for quality evaluation and sorting of agricultural products. Journal of Agricultural Engineering Research 49, 85-98.

Chen, Y.R., Chao, K.L., Kim, M.S., 2002. Machine vision technology for agricultural applications. Computers and Electronics in Agriculture 36 (2-3), 173-191.

Cheng, X., Chen, Y.R., Tao, Y., Wang, C.Y., Kim, M.S., Lefcourt, A.M., 2004. A novel integrated PCA and FLD method on hyperspectral image feature extraction for cucumber chllling damage inspection. Transactions of the ASAE 47 (4), 1313-1320.

Cho, B.K., Chayaprasert, W., Stroshine, R.L., 2008. Effects of internal browning and watercore on low field $(5.4 \mathrm{MHz})$ proton magnetic resonance measurements of T-2 values of whole apples. Postharvest Biology and Technology 47 (1), 81-89.

Cho, N., Song, S.J., Kim, S., Yoo, H.J., 2005. A 5.1- $\mu$ WUHF RFID tag chip integrated with sensors for wireless environmental monitoring. In: Esscirc 2005: Proceedings of the 31st European Solid-State Circuits Conference, pp. 279-282.

Delwiche, M.J., Arévalo, H., Mehlschau, J.J., 1996. Second generation impact force response fruit firmness sorter. Transactions of the ASAE 39 (3), 1025-1033.

di Natale, C., Macagnano, A., Martinelli, G., Paolesse, R., Proietti, E., Dǐamico, A., 2001. The evaluation of quality of post-harvest oranges and apples by means of an electronic nose. Sensors and Actuators B 78, 26-31.

Diezma-Iglesias, B., Ruiz-Altisent, M., Barreiro, P., 2004. Detection of internal quality in seedless watermelon by acoustic impulse response. Biosystems Engineering 88 (2), 221-230.

Digital-Photography-Review, 2010. Fujifilm announces Super CCD EXR 2008. Available from http://www.dpreview.com/news/0809/08092210fujifilmEXR.asp [cited 8.03.10].

Dogan, A., Siyakus, G., Severcan, F., 2007. FTIR spectroscopic characterization of irradiated hazelnut (Corylus avellana L.). Food Chemistry 100 (3), 1106-1114.

Du, C.-J., Sun, D.-W., 2006. Learning techniques used in computer vision for food quality evaluation: a review. Journal of Food Engineering 72 (1) 39-55.

Du, C.J., Sun, D.W., 2004. Recent developments in the applications of image processing techniques for food quality evaluation. Trends in Food Science \& Technology 15 (5), 230-249.

Dunn, M.T., 2007. Applications of Vision Sensing in Agriculture. University of Southern Queensland, Australia.

Edan, Y., Pasternak, H., Shmulevich, I., Rachmani, D., Guedalia, D., Grinberg, S., Fallik, E., 1997. Color and firmness classification of fresh market tomatoes. Journal of Food Science 62 (4), 793-796

Elbatawi, I.E., 2008. An acoustic impact method to detect hollow heart of potato tubers. Biosystems Engineering 100 (2), 206-213.

ElMasry, G., Wang, N., ElSayed, A., Ngadi, M., 2007. Hyperspectral imaging for nondestructive determination of some quality attributes for strawberry. Journal of Food Engineering 81 (1), 98-107.

Fekete, A., Felföldi, J., 2000. System for fruit firmness evaluation. In: Paper Read at Proc. Intnl. Conf. Agricultural Engineering, Warwick, UK.

Fekete, A., Olasz, A., 2005. Optical method for fruit surface irregularity measurement. In: Proceedings of the ASAE Annual Intl. Meeting. ASAE.

Forbes, K.A., Tattersfield, G.M., 1999. Estimating fruit volume from digital images. In: Proceedings of the 5th Africon Conference in Africa: IEEE.

François, I.M., Wins, H., Buysens, S., Godts, C., Van Pee, E., Nicolaï, B., De Proft, M., 2008. Predicting sensory attributes of different chicory hybrids using physicochemical measurements and visible/near infrared spectroscopy. Postharvest Biology and Technology 49 (3), 366-373.

Gambhir, P.N., Choi, Y.J., Slaughter, D.C., Thompson, J.F., McCarthy, M.J., 2005. Proton spin-spin relaxation time of peel and flesh of navel orange varieties exposed to freezing temperature. Journal of the Science of Food and Agriculture 85 (14), 2482-2486.

García-Ramos, F.J., Ortiz-Cañavate, J., Ruiz-Altisent, M., Díez, J., Flores, L., Homer, I., Chávez, J.M., 2003. Development and implementation of an on-line impact sensor for firmness sensing of fruits. Journal of Food Engineering 58 (1), 5357.

García-Ramos, F.J., Valero, C., Homer, I., Ortiz-Cañavate, J., Ruiz-Altisent, M., 2005. Non-destructive fruit firmness sensors: a review. Spanish Journal of Agricultural Research 3 (1), 61-73.

Garret, R.E., Furry, R.B., 1972. Velocity of sonic pulses in apples. Transactions of the ASAE 15 (4), 770-774

Gibson, A.P., Hebden, J.C., Arridge, S.R., 2005. Recent advances in diffuse optical imaging. Physics in Medicine and Biology 50 (4), R1-R43.

Gomez, A.H., Wang, J., Hu, G., Pereira, A.G., 2006. Electronic nose technique potential monitoring mandarin maturity. Sensors and Actuators B: Chemical 113 (1), 347-353.

Gómez, A.H., Wang, J., Hu, G., Pereira, A.G., 2008. Monitoring storage shelf life of tomato using electronic nose technique. Journal of Food Engineering 85 (4), 625-631.

Gonda, L., Cugnasca, C.E., 2006. A proposal of greenhouse control using wireless sensor networks. In: In Computers in Agriculture and Natural Resources, 4th World Congress Conference, Orlando, FL, USA

Goni, O., Munoz, M., Ruiz-Cabello, J., Escribano, M.I., Merodio, C., 2007. Changes in water status of cherimoya fruit during ripening. Postharvest Biology and Technology 45 (1), 147-150.

Gowen, A.A., O’Donnell, C.P., Cullen, P.J., Downey, G., Frias, J.M., 2007. Hyperspectral imaging-an emerging process analytical tool for food quality and safety control. Trends in Food Science \& Technology 18 (12), 590-598. 
Gowen, A.A., O’Donnell, C.P., Taghizadeh, M., Cullen, P.J., Frias, J.M., Downey, G., 2008. Hyperspectral imaging combined with principal component analysis for bruise damage detection on white mushrooms (Agaricus bisporus). Journal of Chemometrics 22 (3-4), 259-267.

Gowen, A.A., Tiwari, B.K., Cullen, P.J., McDonnell, K., O’Donnell, C.P., 2010. Applications of thermal imaging in food quality and safety assessment. Trends in Food Science \& Technology 21 (4), 190-200.

Graves, M., Batchelor, B., 2003. Machine Vision for the Inspection of Natural Products. Springer.

Greensill, C.V., Wolfs, P.J., Spiegelman, C.H., Walsh, K.B., 2001. Calibration transfer between PDA-based NIR spectrometers in the NIR assessment of melon soluble solids content. Applied Spectroscopy 55 (5), 647-653.

Gunasekaran, S., Irudayaraj, J., 2001. Optical methods: visible, NIR and FTIR spectroscopy. In: Nondestructive Food Evaluation. Techniques to Analyse Properties and Quality. Marcel Dekker Inc., New York, USA.

Gutiérrez, A., Ramos, P., Moltó, E., 1999. Desarrollo de una máquina para la detección de mandarinas bufadas basada en sensores de firmeza. Paper read at Proceedings VIII Congreso Nacional de Ciencias Hortícolas, 1999, at Murcia, Spain.

Guyer, D., Yang, X.K., 2000. Use of genetic artificial neural networks and spectral imaging for defect detection on cherries. Computers and Electronics in Agriculture 29 (3), 179-194.

Haff, R.P., Slaughter, D.C., Sarig, Y., Kader, A., 2006. X-ray assessment of translucency in pineapple. Journal of Food Processing and Preservation 30 (5), 527-533.

Hansen, J.D., Schlaman, D.W., Haff, R.P., Yee, W.L., 2005. Potential postharvest use of radiography to detect internal pests in deciduous tree fruits. Journal of Entomological Science 40 (3), 255-262.

Heinemann, P.H., Varguese, Z.A., Morrow, C.T., Sommer III, H.J., Crassweller, R.M., 1995. Machine vision inspection of 'Golden Delicious' apples. Applied Engineering in Agriculture 11 (6), 6.

Hernández-Sánchez, N. 2006. Development of on-line NMR applications for the evaluation of fruit internal quality. Ingeniería Rural, Universidad Politécnica de Madrid, Madrid.

Hernández-Sánchez, N., Barreiro-Elorza, P., Ruiz-Cabello, J., 2009. Nuclear magnetic resonance for internal quality evaluation in horticultural products. In: Sun, D.-W. (Ed.), Optical Monitoring of Fresh and Processed Agricultural Crops. Contemporary Food Engineering Series. CRC Press.

Hernandez-Sanchez, N., Barreiro, P., Ruiz-Altisent, M., Ruiz-Cabello, J., FernandezValle, M.E., 2004. Detection of freeze injury in oranges by magnetic resonance imaging of moving samples. Applied Magnetic Resonance 26 (3), 431-445.

Hernandez-Sanchez, N., Barreiro, P., Ruiz-Cabello, J., 2006. On-line identification of seeds in mandarins with magnetic resonance imaging. Biosystems Engineering 95 (4), 529-536.

Hernandez-Sanchez, N., Hills, B.P., Barreiro, P., Marigheto, N., 2007. An NMR study on internal browning in pears. Postharvest Biology and Technology 44 (3), 260-270.

Herrero-Langreo, A., 2010. Spectral machine vision for peach ripeness assessmen in harvest and postharvest. PhD Dissertation. Department of Agricultural Engineering, Universidad Politécnica de Madrid, Madrid, Spain.

Hills, B.P., 2006. Applications of low-field NMR to food science. Annual Reports on NMR Spectroscopy 58, 177-230.

Hills, B.P., Clark, C.J., 2003. Quality Assessment of Horticultural Products by NMR. In Annual Reports on NMR Spectroscopy. Academic Press.

Hills, B.P., Wright, K.M., 2006. Motional relativity and industrial NMR sensors. Journal of Magnetic Resonance 178 (2), 193-205.

Howarth, M.S., Ioannides, Y., 2002. Sinclair IQ-firmness tester. In: Paper Read at Proc. Intnl. Conf. Agricultural Engineering, Budapest, Hungry.

Hryniewicz, M., Sotome, I., Anthonis, J., Ramon, H., De Baerdemaeker, J., 2005. 3D surface modeling with stereovision. In: Paper Read at 3rd Intl. Symp. on Applications of Modeling as an Innovative Technology in the Agri-Food Chain: MODEL-IT 2005.

Huang, Y.-b., Lan, Y.-b., Hoffmann, W.C., Lacey, R.E., 2007. Multisensor data fusion for high quality data analysis and processing in measurement and instrumentation. Journal of Bionic Engineering 4 (1), 53-62.

Huarng, L., Chen, P., Upadhyaya, S., 1993. Determination of acoustic vibration modes in apples. Transactions of the ASAE 36 (5), 1423-1429.

Hung, Y.C., Prussia, S.E., Ezeike, G.O.I., 1999. Nondestructive firmness sensing using a laser air-puff detector. Postharvest Biology and Technology 16 (1), 15-25.

IEEE, 2003. Wireless Medium Access Control (MAC) and Physical Layer (PHY) Specifications. Specifications for Low-Rate Wireless Personal Area Networks (LR-WPANs). IEEE Standard. 802.15.4. The Institute of Electrical and Electronics Engineers Inc. The Institute of Electrical and Electronics Engineers Inc., New York, USA.

Inon, F.A., Garrigues, J.M., Garrigues, S., Molina, A., de la Guardia, M., 2003. Selection of calibration set samples in determination of olive oil acidity by partial least squares-attenuated total reflectance-Fourier transform infrared spectroscopy. Analytica Chimica Acta 489 (1), 59-75.

Jancsók, P.T., Clijmans, L., Nicolaï, B.M., De Baerdemaeker, J., 2001. Investigation of the effect of shape on the acoustic response of [']conference' pears by finite element modelling. Postharvest Biology and Technology 23 (1), 1-12.

Jarimopas, B., Jaisin, N., 2008. An experimental machine vision system for sorting sweet tamarind. Journal of Food Engineering 89 (3), 291-297.

Jay, M., Lancelin, N., Lichou, J., Chapon, J.F., Guinot, E., Brunninck, M., 2000. Qualité des abricots: analyse sur les varietés Goldrich et Hargrand. Infos Ctifl 161, 3438 .

Jedermann, R., Ruiz-Garcia, L., Lang, W., 2009. Spatial temperature profiling by semi-passive RFID loggers for perishable food transportation. Computers and Electronics in Agriculture 65 (2), 145-154.
Jiang, L., Zhu, B., Cheng, X., Luo, Y., Tao, Y., 2009. 3D surface reconstruction and analysis in automated apple stem-end/calyx identification. Transactions of the ASAE 52 (5), 1775-1784.

Jordan, R.B., Clark, C.J., 2004. Sorting of kiwifruit for quality using drop velocity in water. Transactions of the ASAE 47 (6), 1991-1998.

Kader, A.A., 2001. Quality assurance of harvested horticultural perishables. In: Paper Read at 4th Intl. Conf. on Postharvest.

Katayama, T., Imo, K., Okamoto, T., Kaizu, Y., Tsukano, K., 2003. Discrimination of Strawberry Class Using 3D Image Processing. Journal of the Japanese Society of Agricultural Machinery 65 (2), 71-76.

Kato, K., 1997. Electrical density sorting and estimation of soluble solids content of watermelon. Journal of Agricultural Engineering Research 67 (2), 161-170.

Kemsley, E.K., Tapp, H.S., Binns, R., Mackin, R.O., Peyton, A.J., 2008. Feasibility study of NIR diffuse optical tomography on agricultural produce. Postharvest Biology and Technology 48 (2), 223-230.

Kanali, C., Murase, H., Honami, N., 1998. Three-dimensional shape recognition using a charge-simulation method to process primary image features. Journal of Agricultural Engineering Research 70 (2), 195-208.

Kim, M.S. Chen, Y.-R, Cho, B.-K, Chao, K., Yang, C.-C., Lefcourt, A.M., Chan, D., 2007. Hyperspectral reflectance and fluorescence line-scan imaging for online defect and fecal contamination inspection of apples. Sensing and Instrumentation for Food Quality and Safety $1,9$.

Kim, M.S., Chen, Y.R., Mehl, P.M., 2001. Hyperspectral reflectance and fluorescence imaging system for food quality and safety. Transactions of the ASAE 44 (3) 721-729.

Kim, S.M., McCarthy, M.J., 2006. Analysis of characteristics of in-line magnetic resonance sensor. In: Advanced Nondestructive Evaluation I, Pts 1 and 2, Proceedings 321-323: 1221-1224

Kim, S.M., Milczarek, R., McCarthy, M., 2008. Fast detection of seeds and freeze damage of mandarines using magnetic resonance imaging. Modern Physics Letters B 22 (11), 941-946.

Lammertyn, J., Dresselaers, T., Van Hecke, P., Jancsok, P., Wevers, M., Nicolai, B.M. 2003a. Analysis of the time course of core breakdown in 'Conference' pears by means of MRI and X-ray CT. Postharvest Biology and Technology 29 (1), 19-28.

Lammertyn, J., Dresselaers, T., Van Hecke, P., Jancsok, P., Wevers, M., Nicolai, B.M., 2003b. MRI and X-ray CT study of spatial distribution of core breakdown in 'Conference' pears. Magnetic Resonance Imaging 21 (7), 805-815.

Lammertyn, J., Dresselaers, T., Van Hecke, P., Jancsók, P., Wevers, M., Nicolaï, B.M. 2003c. MRI and X-ray CT study of spatial distribution of core breakdown in ‘Conference' pears. Magnetic Resonance Imaging 21 (7), 805-815.

Lammertyn, J., Nicolai, B., Ooms, K., De Smedt, V., De Baerdemaeker, J., 1998. Nondestructive measurement of acidity, soluble solids, and firmness of Jonagold apples using NIR-spectroscopy. Transactions of the ASAE 41 (4), 1089-1094.

Lammertyn, J., Peirs, A., De Baerdemaeker, J., Nicolaï, B., 2000. Light penetration properties of NIR radiation in fruit with respect to non-destructive quality assessment. Postharvest Biology and Technology 18 (2), 121-132.

Lazcka, O., Campo, F.J.D., Muñoz, F.X., 2007. Pathogen detection: a perspective of traditional methods and biosensors. Biosensors and Bioelectronics 22 (7) $1205-1217$

Lea-Cox, J.D., Kantor, G., Anhalt, J., Ristvey, A., Ross, D.S., 2007. A wireless sensor network for the nursery and greenhouse industry. In: Southern Nursery Association Research Conference, vol. 52 .

Lebrun, M., Plotto, A., Goodner, K., Ducamp, M.-N., Baldwin, E., 2008. Discrimination of mango fruit maturity by volatiles using the electronic nose and gas chromatography. Postharvest Biology and Technology 48 (1), 122-131.

Leung, A., Shankar, P.M., Mutharasan, R., 2007. A review of fiber-optic biosensors. Sensors and Actuators B: Chemical 125 (2), 688-703.

Li, C., Heinemann, P., Sherry, R., 2007. Neural network and Bayesian network fusion models to fuse electronic nose and surface acoustic wave sensor data for apple defect detection. Sensors and Actuators B: Chemical 125 (1), 301-310.

Li, C., Krewer, G.W., Ji, P., Scherm, H., Kays, S.J., 2010. Gas sensor array for blueberry fruit disease detection and classification. Postharvest Biology and Technology 55 (3), 144-149.

Liu, A., 2008. Towards development of chemosensors and biosensors with metaloxide-based nanowires or nanotubes. Biosensors and Bioelectronics 24 (2), 167-177.

Liu, G., Ying, Y., 2003. Application of Bluetooth technology in greenhouse environment, monitor and control. Journal of Zhejiang University, Agricultural and Life Science 29, 329-334.

Liu, H., Meng, Z., Cui, S., 2007. A wireless sensor network prototype for environmental monitoring in greenhouses. In: Paper Read at International Conference on Wireless Communications, Networking and Mobile Computing (WiCom 2007), 21-25 September 2007, at Shanghai, China.

Liu, M., Hu, S., Lin, H., Zhou, X., Xu, H., 2008. Method for Detecting Fruit Quality Through Laser-Induced Fluorescence Hyperspectral Image and its Equipment. Univ. Jiangxi Agric.

Liu, Y., Sun, X., Ouyang, A., 2010. Nondestructive measurement of soluble solid content of navel orange fruit by visible-NIR spectrometric technique with PLSR and PCA-BPNN. LWT - Food Science and Technology 43 (4), 602-607.

Lopez, J.A., Soto, F., Sanchez, P., Iborra, A., Suardiaz, J., Vera, J.A., 2009. Development of a sensor node for precision horticulture. Sensors 9 (5), 3240-3255.

Lowe, C.R., 1999. Chemoselective biosensors. Current Opinion in Chemical Biology 3 (1), 106-111.

Lu, R., Chen, Y.R., 1998. Hyperspectral imaging for safety inspection of foods and agricultural products. In: Paper Read at SPIE Proceedings-Pathogen Detection and Remediation for Safe Eating. 
Lu, R., Peng, Y., 2007. Development of a multispectral imaging prototype for real-time detection of apple fruit firmness. Optical Engineering 46 (12).

Lu, R., Tipper, N.C., 2009. A portable device for the bioyield detection to measure apple firmness. Applied Engineering in Agriculture 25 (4), 517-523.

Lleo, L., Barreiro, P., Ruiz-Altisent, M., Herrero, A., 2009. Multispectral images of peach related to firmness and maturity at harvest. Journal of Food Engineering $93(2), 229-235$.

Macnish, A.J., Joyce, D.C., Shorter, A.J., 1997. A simple non-destructive method for laboratory evaluation fo fruit firmness. Australian Journal of Experimental Agriculture, 37.

Marigheto, N., Duarte, S., Hills, B.P., 2005. NMR relaxation study of avocado quality. Applied Magnetic Resonance 29 (4), 687-701.

Marigheto, N., Venturi, L., Hills, B., 2008. Two-dimensional NMR relaxation studies of apple quality. Postharvest Biology and Technology 48 (3), 331-340.

Marigheto, N., Wright, K., Hills, B.P., 2006. NMR protocol for on-line Brix determination. Applied Magnetic Resonance 30 (1), 13-23.

McGlone, V.A., Ko, S.M.W., Jordan, R.B., 1999. Noncontact fruit firmness measurement by the laser air-puff method. Transactions of the ASAE 42 (5), pp. 1391-1297.

Mehinagic, E., Royer, G., Symoneaux, R., Bertrand, D., Jourjon, F., 2004. Prediction of the sensory quality of apples by physical measurements. Postharvest Biology and Technology 34 (3), 257-269.

Mello, L.D., Kubota, L.T., 2002. Review of the use of biosensors as analytical tools in the food and drink industries. Food Chemistry 77 (2), 237-256.

Menesatti, P., Costa, C., Paglia, G., Pallottino, F., D’Andrea, S., Rimatori, V., Aguzzi, J., 2008. Shape-based methodology for multivariate discrimination among Italian hazelnut cultivars. Biosystems Engineering 101 (4), 417-424.

Mielle, P., Marquis, F., 2001. One-sensor electronic olfactometer for rapid sorting of fresh fruit juices. Sensors and Actuators B: Chemical 76 (1-3), 470-476.

Milczarek, R.R., Saltveit, M.E., Garvey, T.C., McCarthy, M.J., 2009. Assessment of tomato pericarp mechanical damage using multivariate analysis of magnetic resonance images. Postharvest Biology and Technology 52 (2), 189-195.

Miller, W.M., Wardowski, W.F., Grierson, W., 2006. Separation and grading of freezedamaged fruit. In: Wardowski, W.F., Miller, W.M., Hall, D.J., Grierson, W. (Eds.), Fresh Citrus Fruits. Fla. Sci. Soc., Inc., Longboat Key, FL.

Moltó, E., Selfa, E., Pons, R., Fornes, I., 1996. Non-destructive measuring firmness using impact sensors. In: Paper Read at Proc. Intnl. Conf. on Agricultural Engineering, Madrid, Spain.

Montrose Technologies, I., 2010. Technical documentation of their products. Available from http://www.montrose-tech.com [cited 27.02.10].

Morais, R., Fernandes, M.A., Matos, S.G., Serodio, C., Ferreira, P., Reis, M., 2008. A ZigBee multi-powered wireless acquisition device for remote sensing applications in precision viticulture. Computers and Electronics in Agriculture 62 (2), 94-106.

Moreda, G.P., Ortiz-Canavate, J., Garcia-Ramos, F.J., Ruiz-Altisent, M., 2009. Nondestructive technologies for fruit and vegetable size determination-a review. Journal of Food Engineering 92 (2), 119-136.

Musse, M., Quellec, S., Cambert, M., Devaux, M.F., Lahaye, M., Mariette, F., 2009. Monitoring the postharvest ripening of tomato fruit using quantitative MRI and NMR relaxometry. Postharvest Biology and Technology 53 (1-2), 22-35.

Nagatani, N., Takeuchi, A., Anwar Hossain, M., Yuhi, T., Endo, T., Kerman, K., Takamura, Y., Tamiya, E., 2007. Rapid and sensitive visual detection of residual pesticides in food using acetylcholinesterase-based disposable membrane chips. Food Control 18 (8), 914-920.

Nayak, M., Kotian, A., Marathe, S., Chakravortty, D., 2009. Detection of microorganisms using biosensors-a smarter way towards detection techniques. Biosensors and Bioelectronics 25 (4),661-667.

Nicolaï, B.M., Beullens, K., Bobelyn, E., Hertog, M.L., Schenk, A., Vermeir, S., Lammertyn, J., 2006. Systems to characterise internal quality of fruit and vegetables. Acta Horticulturae 712, 59-66.

Nicolai, B.M., Beullens, K., Bobelyn, E., Peirs, A., Saeys, W., Theron, K.I., Lammertyn, J., 2007. Nondestructive measurement of fruit and vegetable quality by means of NIR spectroscopy: a review. Postharvest Biology and Technology 46, 99-118.

Noh, H.K., Peng, Y., Lu, R., 2007. Integration of hyperspectral reflectance and fluorescence imaging for assessing apple maturity. Transactions of the ASAE 50 (3), 963-971.

Noordam, J.C., 2010. Innovative applications in the agro and food industry 2005. Available from http://www.greenvision.wur.nl/documents/publicaties/ in_de_pers/Algemeen/2005_04_EMVABusinessConference_Innovative\%20Applications\%20in\%20the\%20Agro\%20and\%20Food\%20industry.pdf [cited 15.03.10].

Okayama, T., Qiao, J., Tanaka, H., Kondo, N., Shibusawa, S., 2006. Classification of Shape of Bell Pepper by Machine Vision System. Agricultural Information Research 15 (2), 113-122.

Parsons, N.R., Edmondson, R.N., Song, Y., 2009. Image analysis and statistical modelling for measurement and quality assessment of ornamental horticulture crops in glasshouses. Biosystems Engineering 104 (2), 161-168.

Patel, P.D., 2002.(Bio)sensors for measurement of analytes implicated in food safety: a review. TrAC Trends in Analytical Chemistry 21 (2), 96-115.

Pathange, L.P., Mallikarjunan, P., Marini, R.P., O'Keefe, S., Vaughan, D., 2006. Nondestructive evaluation of apple maturity using an electronic nose system. Journal of Food Engineering 77 (4), 1018-1023.

Pathaveerat, S., Terdwongworakul, A., Phaungsombut, A., 2008. Multivariate data analysis for classification of pineapple maturity. Journal of Food Engineering 89 (2), 112-118

Pearson, T.C., 2001. Detection of pistachio nuts with closes shells using impact acoustics. Applied Engineering in Agriculture 17 (2), 240-253.
Peiris, K.H.S., Dull, G.G., Leffler, R.G., Burns, J.K., Thai, C.N., Kays, S.J., 1998. Nondestructive detection of section drying, an internal disorder in tangerine. Hortscience 33 (2), 310-312.

Peng, Y.K., Lu, R.F., 2007. Prediction of apple fruit firmness and soluble solids content using characteristics of multispectral scattering images. Journal of Food Engineering $82(2), 142-152$.

Peris, M., Escuder-Gilabert, L., 2009. A 21st century technique for food control: electronic noses. Analytica Chimica Acta 638 (1), 1-15.

Pickwell, E., Wallace, V.P., 2006. Biomedical applications of terahertz technology. Journal of Physics D-Applied Physics 39 (17), R301-R310.

Pitre, G., Ettenberg, M.H., Bridges, A., Dahl, R., Crase, B., 2010. Future outlook for the photonics industry 2010. Available from http://www.depsci.com/Documents/NewsRoom/PHOT-MarketOutlookSMM.pdf [cited 3.03.10].

Planton, G., 1991. Tomate-Mesure de la fermeté au Durogel 25. Infos Ctifl 74, 17-20.

Qin, J.W., Lu, R.F., 2008. Measurement of the optical properties of fruits and vegetables using spatially resolved hyperspectral diffuse reflectance imaging technique. Postharvest Biology and Technology 49 (3), 355-365.

Qing, Z.S., Ji, B.P., Zude, M., 2007. Predicting soluble solid content and firmness in apple fruit by means of laser light backscattering image analysis. Journal of Food Engineering 82 (1), 58-67.

Raffo, A., Gianferri, R., Barbieri, R., Brosio, E., 2005. Ripening of banana fruit monitors by water relaxation and diffusion ${ }^{1} \mathrm{H}-\mathrm{NMR}$ measurements. Food Chemistry 89 , 149-158.

Rich, R.L., Myszka, D.G., 2007. Survey of the year 2006 commercial optical biosensor literature. Journal of Molecular Recognition (20), 300-366.

Riyadi, S., Ishak, A.J., Mustafa, M.M., Hussain, A., 2008. Wavelet-based feature extraction technique for fruit shape classification. In: Paper Read at ISMA 08.

Roger, J.M., Chauchard, F., Bellon-Maurel, V., 2003. EPO-PLS external parameter orthogonalisation of PLS application to temperature-independent measurement of sugar content of intact fruits. Chemometrics and Intelligent Laboratory Systems 66 (2), 191-204.

Roy, S., Anantheswaran, R.C., Shenk, J.S., Westerhaus, M.O., Beelman, R.B., 1993. Determination of moisture-content of mushrooms by VIS NIR spectroscopy. Journal of the Science of Food and Agriculture 63 (3), 355-360.

Rudnitskaya, A., Kirsanov, D., Legin, A., Beullens, K., Lammertyn, J., Nicolaï, B.M., Irudayaraj, J., 2006. Analysis of apples varieties - comparison of electronic tongue with different analytical techniques. Sensors and Actuators B: Chemical 116 (1-2), 23-28.

Ruiz-Altisent, M., Lleó, L., Riquelme, F., 2006. Instrumental quality assessment of peaches: fusion of optical and mechanical parameters. Journal of Food Engineering 74 (4), 490-499.

Ruiz-Garcia, L., 2008. Development of Monitoring Applications for Refrigerated Perishable Goods Transportation. Ingenieria Rural, Universidad Politécnica de Madrid, Madrid.

Ruiz-Garcia, L., Barreiro, P., Robla, J.I., 2008. Performance of ZigBee-based wireless sensor nodes for real-time monitoring of fruit logistics. Journal of Food Engineering 87 (3), 405-415.

Ruiz-Garcia, L., Lunadei, L., Barreiro, P., Robla, J.I., 2009. A review of wireless sensor technologies and applications in agriculture and food industry: state of the art and current trends. Sensors 9 (6), 4728-4750.

Saaid, M., Saad, B., Hashim, N.H., Mohamed Ali, A.S., Saleh, M.I., 2009. Determination of biogenic amines in selected Malaysian food. Food Chemistry 113 (4), 1356-1362.

Saevels, S., Lammertyn, J., Berna, A.Z., Veraverbeke, E.A., Di Natale, C., Nicolai, B.M., 2003. Electronic nose as a non-destructive tool to evaluate the optimal harvest date of apples. Postharvest Biology and Technology 30 (1), 3-14.

Saeys, W., Velazco-Roa, M.A., Thennadil, S.N., Ramon, H., Nicolai, B.M., 2008. Optical properties of apple skin and flesh in the wavelength range from 350 to $2200 \mathrm{~nm}$. Applied Optics 47 (7), 908-919.

Sankaran, S., Mishra, A., Ehsani, R., Davis, C., 2010. A review of advanced techniques for detecting plant diseases. Computers and Electronics in Agriculture 72 (1), $1-13$.

Shahin, M.A., Tollner, E.W., Evans, M.D., Arabnia, H.R., 1999. Watercore features for sorting red delicious apples: a statistical approach. Transactions of the ASAE 42 (6), 1889-1896.

Sheppard, N., Willis, H.A., Rigg, J.C., 1985. Names, symbols, definitions and units of quantities in optical spectroscopy. Pure and Applied Chemistry 57 (1), 105-120. SICK-AG, 2010. Technical documentation of their products 2010. Available from http://www.sickivp.se/sickivp/en.html [cited 27.02.10].

Sikorska, E., Gorecki, T., Khmelinskii, I.V., Sikorski, M., Koziol, J., 2005. Classification of edible loils using synchronous scanning fluorescence spectroscopy. Food Chemistry 89 (2), 217-225.

Slaughter, D.C., Obenland, D.M., Thompson, J.F., Arpaia, M.L., Margosan, D.A., 2008. Non-destructive freeze damage detection in oranges using machine vision and ultraviolet fluorescence. Postharvest Biology and Technology 48 (3), 341346.

Slaughter, D.C., Ruiz-Altisent, M., Thompson, J.F., Chen, P., Sarig, Y., Anderson, M., 2009. A Handheld, Low-Mass, Impact Instrument to Measure Nondestructive Firmness of Fruit. Transactions of the ASABE 52 (1), 193-199.

Snopok, B.A., Kruglenko, I.V., 2002. Multisensor systems for chemical analysis: stateof-the-art in Electronic Nose technology and new trends in machine olfaction. Thin Solid Films 418 (1), 21-41.

Steinberg, I.M., Steinberg, M.D., 2009. Radio-frequency tag with optoelectronic interface for distributed wireless chemical and biological sensor applications. Sensors and Actuators B: Chemical 138 (1), 120-125. 
Steinmetz, V., Crochon, M., Bellon-Maurel, V., Garcia Fernandez, J.L., Barreiro-Elorza, P., Verstreken, L., 1996. Sensors for fruit firmness assessment: comparison and fusion. Journal of Agricultural Engineering Research 64 (1), 15-27.

Studman, C.J., 2001. Computers and electronics in postharvest technology-a review. Computers and Electronics in Agriculture 30 (1-3), 109-124.

Sugiura, T., Kuroda, H., Ito, D., Honjo, H., 2001. Correlations between specific gravity and soluble solids concentration in grape berries. Journal of the Japanese Society for Horticultural Science 70 (3), 380-384.

Sugiyama, J.T., Katsurai, T., Hong, J., Koyama, H., Mikuriya, K., 1998. Melon ripeness monitoring by a portable firmness tester. Transactions of the ASAE 41 (4) 121-127.

Syvertsen, J.P., Albrigo, L.G., Dunlop, J.M., Ritenour, M.A., Vachon, R.C., 2005. Growth conditions, crop load and fruit size affect sheepnosing in grapefruit. In: Proceedings of the 118th Annual Meeting of the Florida State Horticultural Society, vol. 118 , pp. 28-34.

Taghizadeh, M., Gowen, A., Ward, P., O'Donnell, C.P., 2010. Use of hyperspectral imaging for evaluation of the shelf-life of fresh white button mushrooms (Agaricus bisporus) stored in different packaging films. Innovative Food Science \& Emerging Technologies 11 (3), 423-431.

Tallada, J.G., Nagata, M., Kobayashi, T., 2006. Detection of bruises in strawberies by hyperspectral imaging. In: 2006 ASABE Annual Intl. Meeting. ASABE, Portland, OR.

Tan, E.S., Slaughter, D.C., Thompson, J.F., 2005. Freeze damage detection in oranges using gas sensors. Postharvest Biology and Technology 35 (2), 177182.

Taniwaki, M., Hanada, T., Sakurai, N., 2009a. Postharvest quality evaluation of "Fuyu" and "Taishuu" persimmons using a nondestructive vibrational method and an acoustic vibration technique. Postharvest Biology and Technology 51 (1) $80-85$.

Taniwaki, M., Hanada, T., Tohro, M., Sakurai, N., 2009b. Non-destructive determination of the optimum eating ripeness of pears and their texture measurements using acoustical vibration techniques. Postharvest Biology and Technology 51 (3), 305-310.

Throop, J.A., Aneshansley, D.J., Anger, W.C., Peterson, D.L., 2005. Quality evaluation of apples based on surface defects: development of an automated inspection system. Postharvest Biology and Technology 36 (3), 281-290.

Todd, B., Phillips, M., Schultz, S.M., Hawkins, A.R., Jensen, B.D., 2009. Low-cost RFID threshold shock sensors. IEEE Sensors Journal 9 (4), 464-469.

Tollner, E.W., Hung, Y.C., Upchurch, B.L., Prussia, S.E., 1992. Relating X-ray absorption to density and water-content in apples. Transactions of the ASAE 35 (6) 1921-1928.

Tu, S.S., Choi, Y.J., McCarthy, M.J., McCarthy, K.L., 2007. Tomato quality evaluation by peak force and NMR spin-spin relaxation time. Postharvest Biology and Technology 44 (2), 157-164.

USDA, 2004. Specialty Crop Competitiveness Act. In 7 U.S.C. 1621 note, edited by U. S. D. o. Agriculture.

Valcke, R., 2008. Prediction of physiological disorders in pears using non-invasive fluorescence techniques. In: Proceedings of the Xth International Pear Symposium, vols. 1 and 2 (800), pp. 979-983.

Valero, C., Ruiz-Altisent, M., Cubeddu, R., Pifferi, A., Taroni, P., Torricelli, A., Valentini, G., Johnson, D.S., Dover, C.J., 2004. Detection of internal quality in kiwi with timedomain diffuse reflectance spectroscopy. Applied Engineering in Agriculture 20 (2), 223-230.

van Tuijl, B., van Os, E., van Henten, E., 2008. Wireless sensor networks: state of the art and future perspective. In: DePascale, S., Mugnozza, G.S., Maggio, A., Schettini, E. (Eds.), Proceedings of the International Symposium on High Technology for Greenhouse System Management, vols. 1 and 2.
Velasco-Garcia, M.N., Mottram, T., 2003. Biosensor technology addressing agricultural problems. Biosystems Engineering 84 (1), 1-12.

Velasco, L.R.I., Medina, C.D., 2004. Soft X-ray imaging for non-destructive detection of the mango pulp weevil (Sternochetus frigidus (Fabr.) infestation in fresh green 'carabao' mango fruits. Philippine Agricultural Scientist 87 (2), 160-164.

Velusamy, V., Arshak, K., Korostynska, O., Oliwa, K., Adley, C., 2010. An overview of foodborne pathogen detection: in the perspective of biosensors. Biotechnology Advances 28 (2), 232-254.

Vergara, A. Llobet, E, Ramírez J.L. Ivanov, P. Fonseca, L Zampolli, S., Scorzoni, A Becker, T., Marco, S., Wöllenstein, J., 2006. An RFID reader with onboard sensing capability for monitoring fruit quality. In: In Eurosensors 2006, Goteborg, Sweden.

Walsh, K.B., 2005. Commercial adoption of technologies for fruit grading, with emphasis on NIRS. In: In FRUTIC '05 (Information and Technologies for Sustainable Fruit and Vegetable Production), Montpellier, France.

Wang, C., Zhao, C.J., Qiao, X.J., Zhang, X., Zhang, Y.H., 2008. The design of wireless sensor networks node for measuring the greenhouse's environment parameters. Computer and Computing Technologies in Agriculture 2 (259), 1037-1046.

Wen, Z., Tao, Y., 2000. Dual-camera NIR/MIR imaging for stem-end/calyx identification in apple defect sorting. Transactions of the ASAE 43 (2), 449-452.

Wentworth, S.M., 2003. Microbial sensor tags. In: 2003 IFT (The Institute of Food Engineering) Annual Meeting, Chicago, IL, USA.

Xia, L., Wei, Z., Wan, M., 2010. Conducting polymer nanostructures and their application in biosensors. Journal of Colloid and Interface Science 341 (1), 1-11.

Xiaobo, Z., Jiewen, Z., Yanxiao, L., Jiyong, S., Xiaoping, Y., 2008. Apples shape grading by Fourier expansion and genetic program algorithm. In: In 4th Intl. Conf. on Natural Computation. IEEE

Xing, J., De Baerdemaeker, J., 2005. Bruise detection on ['Jonagold' apples using hyperspectral imaging. Postharvest Biology and Technology 37 (2), 152-162.

Xing, J., Jancsok, P., De Baerdemaeker, J., 2007. Stem-end/calyx identification on apples using contour analysis in multispectral images. Biosystems Engineering 96 (2), 231-237.

Yang, I.-C., Chen, S., Huang, Y.-I., Hsieh, K.-W., Chen, C.-T., Lu, H.-C., Chang, C.-L., Lin, H.-M., Chen, Y.-L., Chen, C.-C., Lo, Y.M., 2008. RFID-integrated multi-functional remote sensing system for seedling production management. In: 2008 ASABE Annual International Meeting, Providence, RI, USA.

Yang, Q.S., 1996. Apple stem and calyx identification with machine vision. Journal of Agricultural Engineering Research 63 (3), 229-236.

Ying, Y., Jing, H., Tao, Y., Zhang, N., 2003. Detecting stem and shape of pears using Fourier transformation and an artificial neural network. Transactions of the Asae $46(1), 157-162$

Yoo, S., Kim, J., Kim, T., Ahn, S., Sung, J., Kim, D., 2007. A2S: automated agriculture system based on WSN. In ISCE 2007. In: IEEE International Symposium on Consumer Electronics. IEEE.

Zerbini, P.E., Vanoli, M., Grassi, M., Rizzolo, A., Fibiani, M., Cubeddu, R., Pifferi, A. Spinelli, L., Torricelli, A., 2006. A model for the softening of nectarines based on sorting fruit at harvest by time-resolved reflectance spectroscopy. Postharvest Biology and Technology 39 (3), 223-232.

Zhang, D.S., Lu, G.J., 2004. Review of shape representation and description techniques. Pattern Recognition 37 (1), 1-19.

Zhou, Y.M., Yang, X.L., Guo, X.S., Zhou, M.G., Wang, L.R., 2007. A Design of Greenhouse Monitoring \& Control System Based on ZigBee Wireless Sensor Network. In: 2007 International Conference on Wireless Communications, Networking and Mobile Computing, Vols. 1-15, pp. 2563-2567.

Zude, M., Herold, B., Roger, J.M., Bellon-Maurel, V., Landahl, S., 2006. Non-destructive tests on the prediction of apple fruit flesh firmness and soluble solids content on tree and in shelf life. Journal of Food Engineering 77 (2), 254-260. 